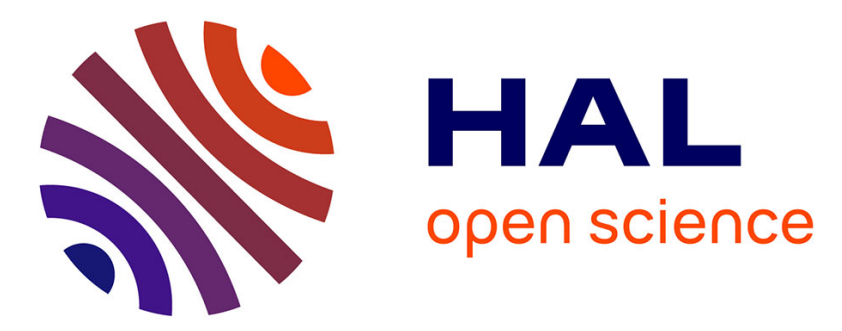

\title{
Sustainable transportation and order quantity: insights from multiobjective optimization
}

Y Bouchery, Asma Ghaffari, Zied Jemai, Jan C Fransoo

\section{To cite this version:}

Y Bouchery, Asma Ghaffari, Zied Jemai, Jan C Fransoo. Sustainable transportation and order quantity: insights from multiobjective optimization. Flexible Services and Manufacturing Journal, 2016, 28 (3), pp.367-396. 10.1007/s10696-016-9240-z . hal-01954465

\section{HAL Id: hal-01954465}

\section{https://hal-normandie-univ.archives-ouvertes.fr/hal-01954465}

Submitted on 13 Dec 2018

HAL is a multi-disciplinary open access archive for the deposit and dissemination of scientific research documents, whether they are published or not. The documents may come from teaching and research institutions in France or abroad, or from public or private research centers.
L'archive ouverte pluridisciplinaire $\mathbf{H A L}$, est destinée au dépôt et à la diffusion de documents scientifiques de niveau recherche, publiés ou non, émanant des établissements d'enseignement et de recherche français ou étrangers, des laboratoires publics ou privés. 


\title{
Sustainable transportation and order quantity: Insights from multiobjective optimization
}

\author{
Yann BOUCHERY*(1), Asma GHAFFARI ${ }^{(2)}$, Zied JEMAI ${ }^{(2),(3)}$, Jan FRANSOO ${ }^{(4)}$ \\ (1) Ecole de Management de Normandie, Axe Logistique Terre Mer Risque \\ 30 Rue de Richelieu, 76087 Le Havre, France \\ (2) Laboratoire Génie Industriel, Ecole Centrale Paris \\ Grande Voie des Vignes, 92290 Chatenay-Malabry, France \\ (3) OASIS-ENIT, University of Tunis El Manar \\ BP 37, Le Belvedere 1002 Tunis, Tunisia \\ (4) Eindhoven University of Technology, School of Industrial Engineering \\ P.O. Box 513, $5600 \mathrm{MB}$ Eindhoven, the Netherlands
}

March 14, 2016

\begin{abstract}
This article applies multiobjective optimization to show how the tradeoffs between cost and carbon emissions may be obtained in the context of sustainable operations. We formulate a model where transportation mode selection and order quantity decisions are considered jointly. We derive structural properties of the model and develop several insights. First, we show that switching to a greener mode of transportation while continuing to optimize the total logistics costs function may lead to a dominated solution. Second, we prove that the modal shift occurs only under strong carbon emissions reduction requirements. Third, we show that the efficient frontier is non-convex and we analyze some implications. Finally, we analyze the impacts of an increase in truck capacity. The results are illustrated through an example of a French retailer.
\end{abstract}

* Corresponding author: Yann Bouchery, ybouchery@em-normandie, Tel: +33232925960 


\section{Introduction}

Environmental and social awareness has considerably increased since the Brundtland report's publication (World Commission on Environment and Development, 1987). Nowadays, many leading companies worldwide are committed in creating value for a broader set of stakeholders instead of focusing solely on creating profits for shareholders or owners. In line with this trend, the number of articles on sustainable operations has drastically increased these last years. We refer to Linton et al. (2007), Srivastava (2007), Seuring and Müller (2008), Kleindorfer et al. (2009), Dekker et al. (2012), Tang and Zhou (2012) and Govindan et al. (2014) for reviews. By acknowledging the different dimensions of sustainability, sustainable operations aim at optimizing several objectives. In this context, companies may identify situations where the objectives may be improved simultaneously, i.e. win-win situations. However, these situations may become more difficult to find as more sustainable practices are deployed. For instance, in an article focusing on cost and carbon emissions objectives, Caro et al. (2013) assume that "firms have exhausted all their carbon abatement initiatives that are profitable in the absence of external incentives", i.e. that win-win situations are unavailable. An increasing number of companies also start thinking that "sustainability can only be attained by optimizing seemingly conflicting targets" (DHL, 2010). In this case, a company interested in sustainable operations seeks to identify the most favorable trade-off between the considered objectives. This leads Fransoo et al. (2014) to consider that "this naturally leads to multiobjective considerations in order to analyze the tradeoff between economic and environmental performance measures" (p. 1). Accordingly, this article applies multiobjective optimization to a decision problem related to sustainable operations in order to show how to obtain the tradeoffs between different types of objectives. The aim of multiobjective optimization is to identify particular solutions such that, when attempting to improve an objective further, other objectives suffer as a result (Ehrgott, 2005). These solutions are called efficient or Pareto optimal and they correspond to the tradeoffs that are of interest for companies interested in sustainable operations.

The model developed consists of a joint transportation mode selection and order quantity optimization

problem. We indeed acknowledge that inventory and transportation decisions are strongly interrelated. However, there is a lack of articles on sustainable operations explicitly addressing this issue. We focus on two objective functions, i.e., cost and carbon emissions. Our multiobjective optimization results enable showing that switching to a greener mode of transportation while continuing to optimize the total logistics costs function may lead to a dominated solution (such that it is possible to reach the same level of carbon emissions with a lower cost by solely adjusting the order quantity). Second, we prove that a shift towards 
a more carbon-efficient mode of transportation is interesting only for strong carbon emissions reduction requirements (i.e., for high carbon emissions reduction target or for high carbon price). Otherwise, order quantity adjustments may enable efficiently greening the supply chain. Third, we show that the efficient frontier (i.e., the set of efficient solutions) is non-convex. This structural property is of great importance as this implies that some non-supported solutions exist (see e.g. Geoffrion (1968) for more details about non-supported solutions). This type of solutions cannot be generated by using a linear combination of the objectives. Thus, using carbon pricing when facing a non-convex efficient frontier may provide a misleading impression to the decision maker as the non-supported solutions would be hidden.

The article is organized as follows. The related literature is reviewed in Section 2. Section 3 is then devoted to the presentation of the model, to the multiobjective optimization results and to the presentation of an example. We also analyze in Section 3 the impacts of using carbon pricing and the impacts of extending vehicle capacity. Finally, Section 4 is devoted to the conclusion and to future research directions.

\section{Literature review and contribution}

This article is directly connected to two main fields of the literature on sustainable supply chains, i.e., order quantity models and transportation mode selection.

First, several articles on order quantity decisions with carbon emissions considerations have recently been proposed. The classical Economic Order Quantity (EOQ) model has been revisited by considering vehicle emissions costs (Bonney and Jaber, 2011), a constraint on carbon emissions (Chen et al., 2013), the emissions trading scheme (Hua et al., 2011) and four different regulatory policies (Arslan and Turkay, 2013). Bouchery et al. (2012) include sustainability criteria into single and multiechelon EOQ models by using multiobjective optimization. Jaber et al. (2013) revisit the joint economic lot size problem by considering that the companies face different types of emissions trading schemes. Benjaafar et al. (2013) include carbon emissions constraints on single and multi-stage lot-sizing models with a cost minimization objective and consider four regulatory policy settings. Battini et al. (2014) extend the EOQ model by explicitly including transportation modeling. They compare the results obtained with a pure cost model and the results obtained when additionally including environmental costs. Konur and Schaefer (2015) include carbon emissions into the joint replenishment problem. They apply multiobjective optimization and identify the set of efficient solutions for two types of strategies (namely direct and indirect grouping). Based on a set of numerical examples, they identify conditions such that a strategy outperforms the other one both in terms of costs and carbon emissions. The dynamic lot-sizing model has 
also been revisited by Absi et al. (2013), Velázquez-Martínez et al. (2014) and Retel Helmrich et al. (2015) by considering an additional constraint on carbon emissions. Except from Velázquez-Martínez et al. (2014) and Battini et al. (2014), the articles cited above do not take explicitly transportation features into account. As a result, these articles do not account for the impact of order quantity decisions on the load factor even if this could strongly impacts the transportation emissions as shown by Velázquez-Martínez et al. (2014). On the other hand, Velázquez-Martínez et al. (2014) and Battini et al. (2014) do not consider transportation mode selection issues.

The second field of literature related to this work focuses on including carbon emissions concerns into freight transportation mode selection problems. Winebrake et al. (2008) present an energy and environmental analysis model to explore the tradeoffs in an intermodal transportation network. Bauer et al. (2009) especially focus on determining the optimal planning for intermodal rail transportation in order to minimize the carbon emissions from transportation. Cholette and Venkat (2009) present a case study where several modes of transportation are available in a wine supply chain context. Their analysis takes cost, carbon emissions and energy consumption into account. Pan et al. (2013) investigate how freight consolidation may help in decreasing the carbon emissions from transportation. They formulate a carbon emissions minimization model where both road and rail transportation are available. They apply their model for optimizing the carbon emissions of two large retail chains. Leal and D'Agosto (2011) consider the transportation mode selection decision in a case study based on a bio-ethanol supply chain. Socio-environmental considerations are included into the model. Finally, Kopfer et al. (2014) analyze the benefits of considering a heterogeneous fleet of vehicles for vehicle routing problems. The authors show that the fuel consumption (and therefore the carbon emissions) can be reduced by choosing vehicles of an adequate size for transport fulfillment. The impact of inventory decisions such as order quantity decisions are not considered in this stream of literature, as the order quantity are assumed to be given exogenously.

To our knowledge, six articles jointly consider transportation mode selection and inventory optimization problem while explicitly accounting for transportation features. Rosič and Jammernegg (2013) extend the dual sourcing model based on the newsvendor framework by considering the environmental impact of transportation. They analyze two types of regulatory policies, i.e. the carbon tax and the carbon cap-and-trade mechanism. They prove that it is possible to reduce the carbon emissions from transportation without substantially affecting the economic performance of the system if the capand-trade mechanism is applied with appropriate carbon cap setting. In Hoen et al. (2014), a stochastic inventory model is extended to incorporate transport emissions costs. The transport mode and order-up-to level of a base-stock inventory policy are jointly optimized in a single product setting. Hoen et al. (2013) 
extend the previous model to a multiple products settings and study the portfolio effect of setting a global emissions target instead of a per product target. These three articles mainly focus on the relationship between transportation leadtime and safety stock levels by arguing that greener modes of transportation are often slower (and/or less flexible) and that this results in increasing the inventory levels. Our paper focuses on a different aspect of the interaction between transportation mode selection and inventory decisions. Indeed, we consider that order quantity decisions have a strong impact on the transportation mode selection decisions and on the carbon emissions levels. First, greener modes of transportation are often able to carry bigger volumes. Second, the order quantity decisions have an effect on load factors and thus on carbon emissions from transportation. Our model enables investigating such relationship and may be viewed as complementary to the literature focusing on the relationship between transportation leadtime and safety stock levels. To our knowledge, three articles focus on such interaction while explicitly accounting for transportation features. Konur (2014) extends the economic order quantity model to account for full truckload cost structure. The author proposes a carbon constrained model and focuses more particularly on the situations for which the optimal order quantity exceeds one full truckload. The article shows that considering a heterogeneous fleet of trucks may help reducing both cost and carbon emissions. Konur and Schaefer (2014) additionally consider less than truckload tariffs and they analyze the impact of four types of regulatory policies. Finally, Schaefer and Konur (2015) propose an integrated continuous review inventory model with explicit transportation decisions. The model accounts for both truckload and less than truckload transportation. The authors consider two objectives, i.e., the total cost and the total carbon emissions and they propose to approximate the efficient frontier by using linear combinations of the two objectives. The results show that an increase in demand variance and/or in lead time negatively affects both cost and emissions. Unlike Konur (2014) and Konur and Schaefer (2014), we focus here on situations for which the optimal order quantity does not exceed one full vehicle load as this is the case in a large variety of industrial situations. Schaefer and Konur (2015) is seminal in the sense that this is the first article that simultaneously considers the relationship between transportation leadtime and safety stock levels as well as the effect of order quantity levels on load factors. Due to the complexity of the problem, the authors approximate the efficient frontier by applying the weighted sum method. We focus here solely on the effect of order quantity levels on load factors. This enables us to analytically identify the efficient frontier. In addition, Schaefer and Konur (2015) solve the problem for each mode separately. They propose some examples with two modes of transportation and solve the integrated inventory and transportation mode selection problem numerically. We propose here analytical results that 
enable us identifying the efficient frontier when multiple transportation modes are available. Our model may consequently be viewed as complementary to the existing literature.

Our contribution is threefold. First, from a modeling perspective, this article is one of the first studying explicitly the relationship between order quantity and transportation mode decisions with cost and carbon emissions concerns. Our model may be applied with multiple modes of transportation including air, water, rail, road and any type of intermodal combinations. The model may also be used to study the effect of speed reduction as speed is recognized to have some major impacts on costs, fuel consumption (Corbett et al., 2009; Fransoo and Lee, 2013) and safety. The model is flexible enough to account for realistic transportation costs and carbon emissions structures as any type of piecewise linear functions may be considered. Second, from a theoretical perspective, we apply the concept of multiobjective optimization in order to identify the existing tradeoffs that a company can face when jointly optimizing transportation mode selection and order quantity decisions. Multiobjective optimization helps the decision maker to build a conviction of what is possible and to use this knowledge to identify the most valuable trade-off. We identify analytically the set of efficient solutions for the problem. Our third contribution consists in

providing new insights to decision makers. We show that switching to a greener mode of transportation while continuing to optimize the total logistics costs function may lead to a dominated solution. We prove that the modal shift occurs only under strong carbon emissions reduction requirements. We show that the efficient frontier is non-convex and we analyze some implications. Finally, we analyze the impacts of an increase in truck capacity.

\section{Model description and multiobjective optimization results}

\subsection{Model description}

In this article, we consider that several modes of transport are available for inbound transportation. Each mode is characterized by a cost function in the form of a fixed cost (per vehicle) and a variable cost (per product unit). Moreover, a fixed lead time is associated to each mode. The lead time has an effect on the average in-transit inventory level. We also take the capacity of each mode into account. The per shipment transportation cost function is defined as follows $(\lceil x\rceil$ represents the nearest integer $\geq x)$ :

$$
T_{C}(Q)=T_{V C} Q+T_{F C}\left\lceil\frac{Q}{Q_{\max }}\right\rceil+h_{T C} L Q,
$$

with: 
$Q=$ order quantity,

$Q_{\max }=$ transportation mode capacity,

$T_{V C}=$ variable transportation cost per product unit,

$T_{F C}=$ fixed transportation costs per vehicle,

$h_{T C}=$ in-transit inventory holding costs per product unit and time unit,

$L=$ transportation lead time.

The total inventory holding and transportation cost function per time unit is defined as follows:

$$
Z_{C}(Q)=\frac{Q}{2} h_{C}+\frac{D}{Q} O_{C}+T_{C}(Q) \frac{D}{Q}+P_{C} D
$$

with:

$D=$ demand per time unit,

$h_{C}=$ inventory holding costs per product unit and time unit,

$O_{C}=$ fixed order costs,

$P_{C}=$ purchase costs per product unit.

Assume that $Q_{C}^{*}$ is the order quantity that minimizes the total cost function (i.e. $\left.Z_{C}\left(Q_{C}^{*}\right)=Z_{C}^{*}\right)$. Lemma 1 provides a sufficient condition ensuring that the optimal order quantity does not exceed one vehicle load.

Lemma 1. Let $Q_{C}^{*}$ be the order quantity minimizing Expression (2). Assume that $O_{C} \leq \frac{h_{c} Q_{\max }^{2}}{2 D}$, then:

$$
Q_{C}^{*} \leq Q_{\max } \text {. }
$$

All proofs may be found in Appendix A. In the following, we assume that the retailer has no control over the production scheme of the manufacturer (that certainly supplies several other retailers) as in most practical situations. In this case, $O_{C}$ represents the fixed costs for order forms, authorization, receiving, inspection and/or handling of invoice from the supplier (Axsäter, 2006) as transport costs are accounted for separately. These costs are usually small comparing to the costs of requiring a second vehicle for inbound transportation as well as the costs of holding extra inventory. These costs have also been reduced by new technologies such as electronic data interchange or radio frequency identification. Consequently, 
we assume that $Q_{C}^{*} \leq Q_{\max }$ in what follows, i.e., that there is no incentive to order more than a full vehicle. In this case, the cost function to be considered may be expressed as follows:

$$
Z_{C}(Q)=\frac{Q}{2} h_{C}+\frac{D}{Q}\left(O_{C}+T_{F C}\right)+\left(P_{C}+T_{V C}+h_{T C} L\right) D, Q \leq Q_{\max },
$$

We refer to Konur (2014) and references therein for an analysis of the complexity and for providing algorithms to solve the problem in the cases for which the optimal order quantity consists in ordering more than a full vehicle load.

In practice, several transportation tariffs are often available, depending on the shipment quantity. We focus on heavy duty truck transport as an example. The truck capacity is $Q_{\max }=33$ euro pallets. Assume that the logistics provider offers three different tariffs. The first one is a less than truckload tariff with $T_{V C}=30 €$ per pallet and $T_{F C}=0 €$ per truck. A second less than truckload tariff is available if the shipment size is at least 21 pallets. In this case, $T_{V C}=20 €$ per pallet and $T_{F C}=0 €$ per truck. Finally, a full truckload tariff is available with $T_{F C}=600 €$ per truck and $T_{V C}=0 €$ per pallet. Assume that the retailer decides to order 15 pallets. The tariff leads to $450 €$ per shipment. On the other hand, to retailer may over-declare its shipment to 21 pallets to take advantage of the all unit discount less than truckload tariff leading to $420 €$ per shipment. Consequently, the transportation costs function follows a modified all-unit discount structure. This cost structure is commonly used in the literature (see e.g. Chan et al., 2002; Croxton et al., 2003; Rieksts and Ventura, 2008). The per shipment transportation cost as a function of the order quantity (up to the truck capacity) is shown in Figure 1.

We intend to develop a model that enables accounting for realistic transportation costs structures such as the modified all-unit discount cost structure introduced above. To do so, let $Q_{\min } \leq Q_{\max }$ be the minimum amount per shipment to make a mode available. By making use of $Q_{\min }$ and $Q_{\max }$, any type of piecewise linear transportation cost function may be taken into account by considering each piecewise linear segment of the transportation cost function as a separate mode characterized by a fixed cost (per vehicle) and a variable cost (per product unit). Indeed, the minimum and maximum capacity limits enable making the mode available only for the quantities related to the segment under consideration. Consequently, we consider 4 different transportation modes with different cost parameters and minimum quantities for the example above. 


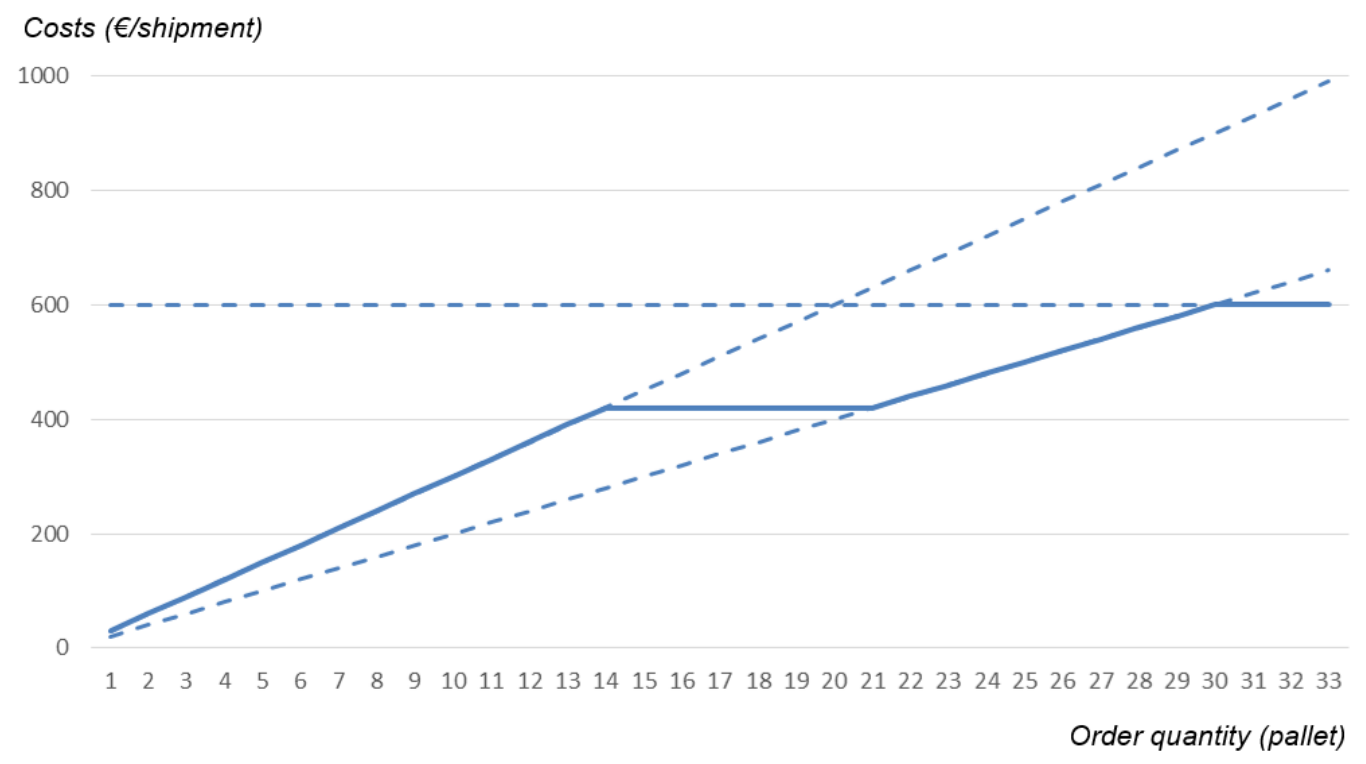

Figure 1: Transportation cost

In the cases for which $Q_{\min } \leq Q_{C}^{*} \leq Q_{\max }$, the order quantity minimizing Equation 3 is obtained easily as $Z_{C}$ is convex on $\left[Q_{\min } ; Q_{\max }\right]$. First, the optimal order quantity without taking the minimum and maximum quantity constraints into account can be calculated. Second, the feasible order quantity which is the closest from this theoretical quantity is selected:

$$
Q_{C}^{*}=\max \left(Q_{\min } ; \min \left(Q_{\max }, \sqrt{\frac{2\left(O_{C}+T_{F C}\right) D}{h_{C}}}\right)\right) .
$$

Modeling carbon emissions across the supply chain is attracting more and more research (see e.g. Scipioni et al., 2012; Sundarakani et al., 2010). In our model, three main sources of carbon emissions may be identified. First, carbon emissions are generated by producing the item. This amount of carbon emissions is independent of the decisions taken by the retailer as we assume that the retailer has no control over the production scheme of the manufacturer. A fixed amount of carbon emissions is thus associated to each item due to production. Second, carbon emissions are generated by inbound transportation. The transportation mode selection as well as the order quantity decisions may affect the amount of carbon emissions generated by inbound transportation. For a given transportation mode, the generated carbon emissions are modeled with a fixed term (due to emissions generated by the vehicle if running empty) and a linear term as a function of the order quantity (due to the extra energy consumption generated by transporting the items). Note that this modeling is commonly used in the transportation literature (see e.g. Pan et al. (2013) for rail and road transportation) and is in accordance with the available methodologies 
for estimating carbon emissions from transportation (see e.g., Demir et al., 2014; NTM, 2008; Hickman et al., 1999). Third, an amount of carbon emissions is associated with the storage of each product unit per time unit. This amount is mainly due to indirect carbon emissions from energy consumption (mainly electricity) in the warehouse. This amount may become important in case of refrigeration.

The total carbon emissions as a function of the order quantity may be expressed as follows for all $Q \geq Q_{\min }:$

$$
Z_{E}(Q)=P_{E} D+\frac{Q}{2} h_{E}+T_{F E}\left\lceil\frac{Q}{Q_{\max }}\right\rceil \frac{D}{Q}+T_{V E} D,
$$

with:

$P_{E}=$ purchase emissions per product unit,

$h_{E}=$ inventory holding emissions per product unit and time unit,

$T_{F E}=$ fixed amount of carbon emissions per shipment,

$T_{V E}=$ variable amount of carbon emissions per product unit.

Assume that $Q_{E}^{*}$ is the order quantity that minimizes the carbon emissions function (i.e. $\left.Z_{E}\left(Q_{E}^{*}\right)=Z_{E}^{*}\right)$. We can observe that $Q_{E}^{*} \leq Q_{\max }$ (there is no incentive to order more than the maximum transportation capacity). It follows that:

$$
Q_{E}^{*}=\max \left(Q_{\min } ; \min \left(Q_{\max ;} \sqrt{\frac{2 T_{F E} D}{h_{E}}}\right)\right) .
$$

\subsection{Multiobjective optimization results}

We consider costs and carbon emissions as two distinct objective functions that have to be minimized. An alternative $a$ is thus said to be dominated if there exists another alternative $b$ that performs at least as good as $a$ on one objective and that performs better than $a$ on the other objective. Multiobjective optimization consists in identifying all the non-dominated alternatives called efficient solutions. The results presented in this section enable identifying the set of efficient solutions in the situations for which multiple modes of transportation are available.

\subsubsection{A single mode of transportation}

As a first step, we identify the set of efficient solutions when considering a single mode of transport. In this case, the only decision variable for the problem is the order quantity and the set of possible values for $Q$ is $A=\left[Q_{\min } ; Q_{\max }\right]$. Let $Z: A \rightarrow \mathfrak{R} \times \mathfrak{R}, Z(a)=\left\{Z_{C}(a) ; Z_{E}(a)\right\}$, for all $a \in A$, with $Z_{C}$ defined by 
Formula 3 representing the total costs and $Z_{E}$ defined by Formula 5 representing the total carbon emissions. $Z(A)=\left\{\left(Z_{C}(Q) ; Z_{E}(Q)\right) \mid Q \in A\right\}$ is the image of $A$ in the criterion space (evaluation space). The set of efficient solutions is a subset of $A$ noted $E$. Its image in the criterion space referred as the efficient frontier is $Z(E)$. Proposition 1 enables identifying the set of efficient solutions in the situations for which a single mode is available. This one can be expressed as a function of $Q_{C}^{*}$ and $Q_{E}^{*}$, the optimal order quantities defined by Formulas 4 and 6 respectively.

Proposition 1: Let $E$ be the set of efficient solutions when considering a single mode of transportation, then:

$$
E=\left[\min \left(Q_{C}^{*} ; Q_{E}^{*}\right) ; \max \left(Q_{C}^{*} ; Q_{E}^{*}\right)\right]
$$

Note that $Q_{C}^{*}<Q_{E}^{*}$ in many practical cases, thus $E=\left[Q_{C}^{*} ; Q_{E}^{*}\right]$. Indeed, $\frac{O_{C}+T_{F C}}{h_{C}}$ is often lower than $\frac{T_{F E}}{h_{E}}$ as the holding cost includes the opportunity cost of the capital tied up into inventory (meaning that $h_{C}$ is high) and as transportation is recognized as a major source of carbon emissions (meaning that $T_{F E}$ is high). Accordingly, we focus on the situations for which $\frac{O_{C}+T_{F C}}{h_{C}}<\frac{T_{F E}}{h_{E}}$ in what follows for the sake of relevance and clarity.

We define now the convexity property for the efficient frontier (which corresponds to a subset of $\mathfrak{R} \times \mathfrak{R})$ and we prove that the efficient frontier is convex when considering a single mode of transportation. Let $S$ be a subset of $\mathfrak{R} \times \mathfrak{R}, \operatorname{Conv}(S)$ is the convex hull of $S$, i.e. the set of all convex combinations of points in $S$. Let $\operatorname{Eff}(S)$ be the efficient frontier of $S$, then $\operatorname{Eff}(S)$ is convex if and only if $\operatorname{Eff}(\operatorname{Conv}(S))=\operatorname{Eff}(S)$.

Proposition 2: Let $Z(E)$ be the efficient frontier when considering a single mode of transportation, then: $Z(E)$ is convex.

Proposition 2 implies that the problem behaves nicely when considering a single mode of transportation. Indeed, all the elements of a convex efficient frontier may be generated by minimizing a weighted sum of objectives. We prove later that the efficient frontier is non-convex when more than one mode of transportation is considered (see Proposition 6). 


\subsubsection{Two modes of transportation}

Consider now that a second mode of transportation (mode 2) is available. In what follows, subscript 1 refers to mode 1 and subscript 2 refers to mode 2. As for mode $1, Q_{C 2}^{*}$ and $Q_{E 2}^{*}$ may be obtained by using Formula 4 and Formula 6 respectively. Moreover, let $Z_{C 2}^{*}=Z_{C 2}\left(Q_{C 2}^{*}\right)$ and $Z_{E 2}^{*}=Z_{E 2}\left(Q_{E 2}^{*}\right)$. Proposition 1 and Proposition 2 are also valid for mode 2. Without loss of generality, we assume that $Z_{C 1}^{*}<Z_{C 2}^{*}$ (mode 1 is less costly than mode 2). Propositions 3 and Lemma 2 restrict the possible number of intersection between $Z_{1}\left(E_{1}\right)$ and $Z_{2}\left(E_{2}\right)$. Note that $|S|$ corresponds to the cardinality of the set $S$.

Proposition 3. Let $Z_{1}\left(E_{1}\right)$ and $Z_{2}\left(E_{2}\right)$ be the efficient frontiers for transportation mode 1 and transportation mode 2 respectively, then:

$$
\left|Z_{1}\left(E_{1}\right) \cap Z_{2}\left(E_{2}\right)\right| \leq 2 .
$$

Lemma 2. Let $Z_{1}\left(E_{1}\right)$ and $Z_{2}\left(E_{2}\right)$ be the efficient frontiers for transportation mode 1 and transportation mode 2 respectively, then:

$$
\begin{gathered}
\text { If } Z_{E 1}^{*}>Z_{E 2}^{*} \text {, then }\left|Z_{1}\left(E_{1}\right) \cap Z_{2}\left(E_{2}\right)\right| \leq 1, \\
\text { Else }\left|Z_{1}\left(E_{1}\right) \cap Z_{2}\left(E_{2}\right)\right| \in\{0 ; 2\} .
\end{gathered}
$$

Figure 2 is an illustration of the possible outcomes when two modes are considered. Figures $2 \mathrm{a}$ to $2 \mathrm{~d}$ illustrate the outcomes when $Z_{E 1}^{*}>Z_{E 2}^{*}$ and Figures $2 \mathrm{e}$ to $2 \mathrm{~g}$ illustrates the outcomes when $Z_{E 1}^{*}<Z_{E 2}^{*}$. The results we present in Proposition 3 and Lemma 2 enable providing additional insights compared to a classical single objective analysis.

If $Z_{E 1}^{*}>Z_{E 2}^{*}$, mode 2 is more expensive but greener. In this case, there exists at most one intersection between the efficient frontiers of the two modes considered separately. In this case, mode 1 will be preferred from a pure cost perspective, and mode two will be preferred if the requirements to green the operations reach a given threshold. This result implies that adjusting the order quantity is the most efficient way of greening operations until a given threshold. This also implies that switching to a greener mode of transportation while continuing to optimize the total logistic cost function may lead to a dominated solution (see Figures 2a and 2c). In this case, the same level of carbon emissions may be obtained with a lower cost by only increasing the order quantity. This result proves that poor decisions may be taken when ignoring the strong interrelationship between inventory control and transportation mode selection. 
Figure 2a

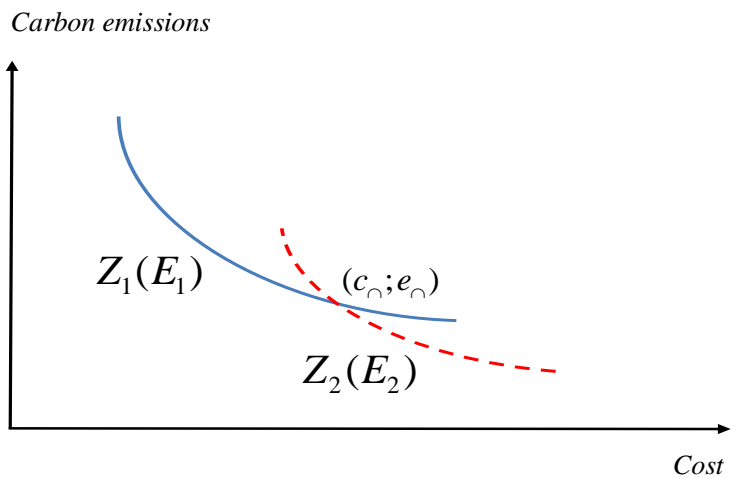

Figure 2c

Carbon emissions

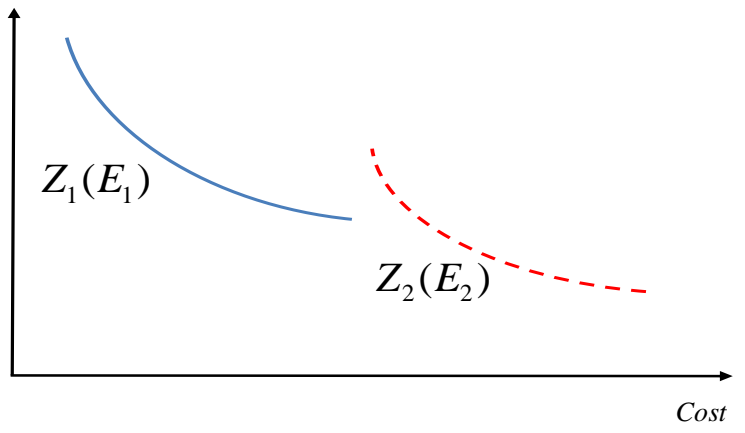

Figure 2e

Carbon emissions

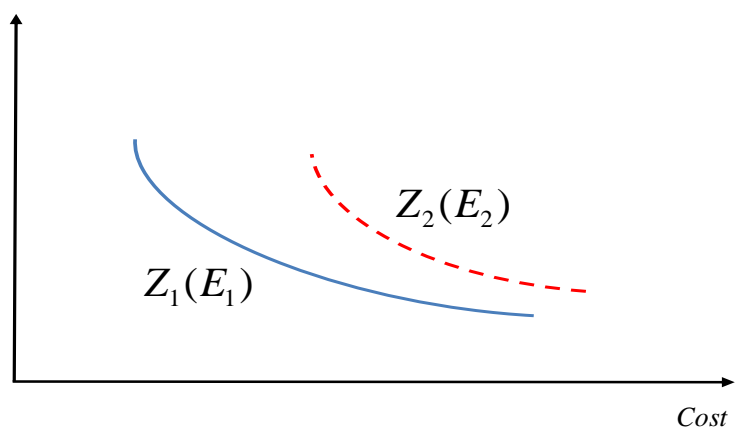

Figure $2 \mathrm{~g}$

Carbon emissions

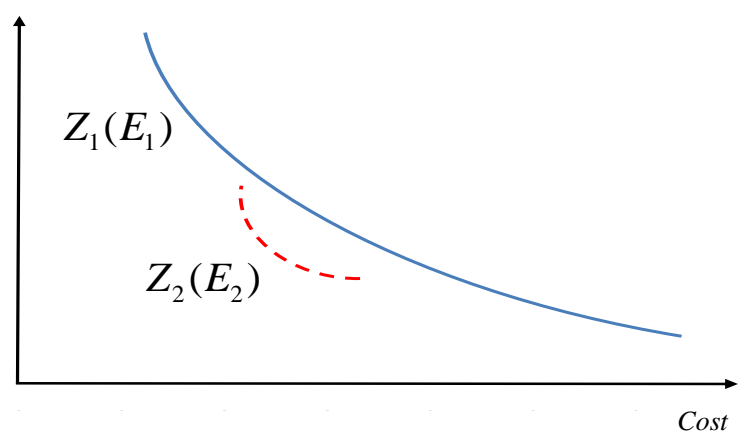

Figure 2b

Carbon emissions

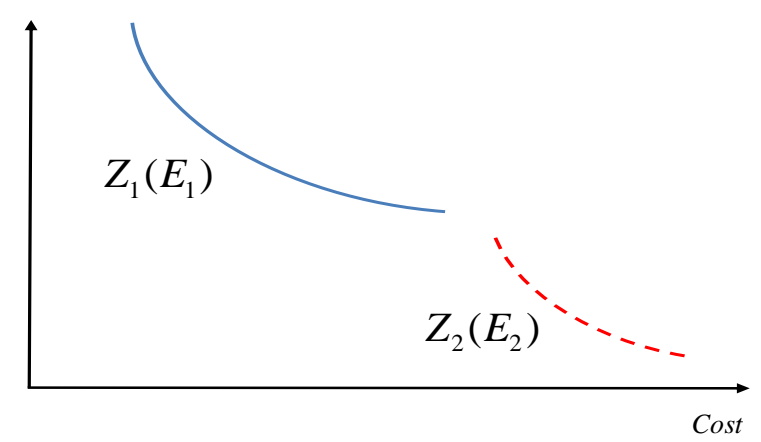

Figure 2d

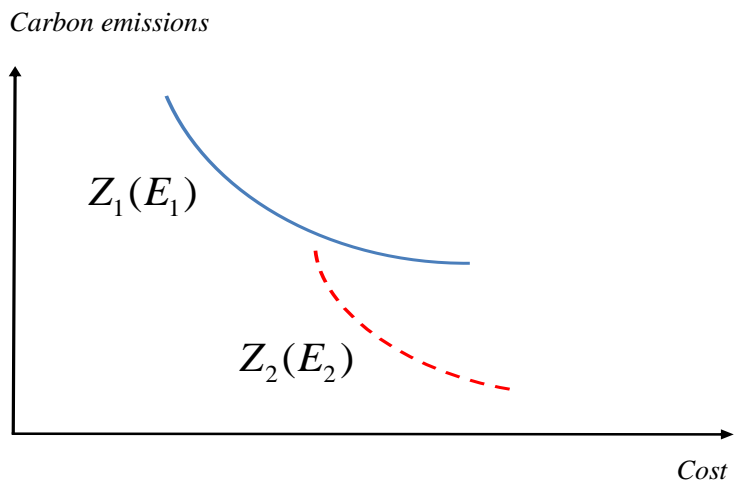

Figure $2 f$

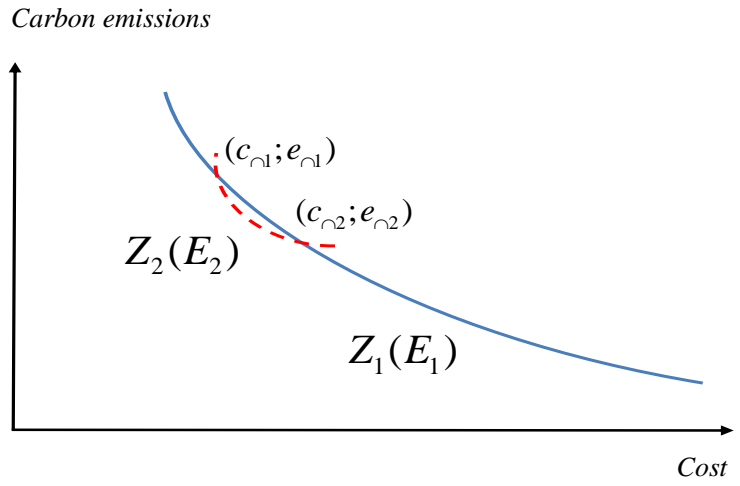

Figure 2: The seven situations when considering two modes of transportation 
If $Z_{C 1}^{*}<Z_{C 2}^{*}$ and $Z_{E 1}^{*}<Z_{E 2}^{*}$, we may expect mode 2 to be out of interest as this is possible to obtain a cheaper solution as well as a greener solution with mode 1. However, our results proves that some solutions obtained with mode 2 may still be efficient in case $\left|Z_{1}\left(E_{1}\right) \cap Z_{2}\left(E_{2}\right)\right|=2$ (see Figure 2f). Mode 2 may indeed be considered in some situations as a better compromise between costs and carbon emissions.

The efficient frontier of the problem with two modes of transportation may be identified by applying Lemma 2 and by acknowledging that $Z_{C 1}^{*}<Z_{C 2}^{*}$ as shown in Propositions 4 and Proposition 5.

Proposition 4. Let $Z(E)$ be the efficient frontier for the problem with two modes of transportation with $Z_{C 1}^{*}<Z_{C 2}^{*}$ and $Z_{E 1}^{*}>Z_{E 2}^{*}$ then:

If $\left|Z_{1}\left(E_{1}\right) \cap Z_{2}\left(E_{2}\right)\right|=1$, then the intersection point is noted $\left\{c_{\cap} ; e_{\cap}\right\}$ and:

$$
Z(E)=\left\{\left(c_{1} ; e_{1}\right) \in Z_{1}\left(E_{1}\right) \mid c_{1} \leq c_{\cap}\right\} \cup\left\{\left(c_{2} ; e_{2}\right) \in Z_{2}\left(E_{2}\right) \mid e_{2} \leq e_{\cap}\right\} .
$$

Else $\left|Z_{1}\left(E_{1}\right) \cap Z_{2}\left(E_{2}\right)\right|=0$ :

If $Z_{1}\left(Q_{E 1}^{*}\right) \subset Z(E)$, then:

$$
Z(E)=Z_{1}\left(E_{1}\right) \cup\left\{\left(c_{2} ; e_{2}\right) \in Z_{2}\left(E_{2}\right) \mid e_{2}<Z_{E 1}^{*}\right\},
$$

Else,

$$
Z(E)=\left\{\left(c_{1} ; e_{1}\right) \in Z_{1}\left(E_{1}\right) \mid c_{1}<Z_{C 2}^{*}\right\} \cup Z_{2}\left(E_{2}\right)
$$

Proposition 5. Let $Z(E)$ be the efficient frontier for the problem with two modes of transportation with $Z_{C 1}^{*}<Z_{C 2}^{*}$ and $Z_{E 1}^{*}<Z_{E 2}^{*}$ then:

If $\left|Z_{1}\left(E_{1}\right) \cap Z_{2}\left(E_{2}\right)\right|=0$ then:

If $Z_{2}\left(Q_{C 2}^{*}\right)$ is efficient then:

$$
Z(E)=\left\{\left(c_{1} ; e_{1}\right) \in Z_{1}\left(E_{1}\right) \mid c_{1}<Z_{C 2}^{*}\right\} \cup Z_{2}\left(E_{2}\right) \cup\left\{\left(c_{1} ; e_{1}\right) \in Z_{1}\left(E_{1}\right) \mid e_{1}<Z_{E 2}^{*}\right\}
$$

Else:

$$
Z(E)=Z_{1}\left(E_{1}\right)
$$

Else $\left|Z_{1}\left(E_{1}\right) \cap Z_{2}\left(E_{2}\right)\right|=2$. Let $\left\{c_{\cap 1} ; e_{\cap 1}\right\}$ and $\left\{c_{\cap 2} ; e_{\cap 2}\right\}$ be the two intersection points and assume that $e_{\cap 2}<e_{\cap 1}$, then:

$$
Z(E)=\left\{\left(c_{1} ; e_{1}\right) \in Z_{1}\left(E_{1}\right) \mid e_{1} \geq e_{\cap 1}\right\} \cup\left\{\left(c_{2} ; e_{2}\right) \in Z_{2}\left(E_{2}\right) \mid e_{\cap 1} \geq e_{2} \geq e_{\cap 2}\right\} \cup\left\{\left(c_{1} ; e_{1}\right) \in Z_{1}\left(E_{1}\right) \mid e_{\cap 2} \geq e_{1}\right\}
$$


Propositions 4 and 5 enable identifying analytically the efficient frontier when two modes of transport are considered. We additionally provide a sufficient condition ensuring that the efficient frontier of the problem with two modes of transportation is non-convex in Proposition 6.

Proposition 6: Let $Z(E)$ be the set of efficient solutions for the problem with two modes of transportation, then:

$$
\text { If } Z(E) \neq Z_{1}\left(E_{1}\right) \text { then } Z(E) \text { is non-convex. }
$$

Proposition 6 proves that the efficient frontier is non-convex in most of practical situations. The fact that the efficient frontier is non-convex as soon a more than one mode of transportation is available implies that some efficient solutions are non- supported ( see e.g. Geoffrion (1968) for more details about nonsupported solutions). These solutions, even if they might be of interest for the decision maker, would not be generated by single objective approaches such as the weighted sum method (pricing emissions is an example of a weighted sum). The multiobjective approach developed in this article enables identifying such non-supported solutions and thus provides a holistic view of the efficient frontier. We provide a discussion on the implications of using a weighted sum method for the problem in Section 3.4.

\subsubsection{More than two modes of transportation}

The study of the global problem with $n>2$ modes of transportation may be conducted as follows. First, the set of efficient solutions for mode $k$ denoted as $E_{k}$ (with corresponding efficient frontier denoted as $\left.Z_{k}\left(E_{k}\right)\right)$ may be identified by using Proposition 1 for all $k \in[1 ; n]$. We assume without loss of generality that for all $k \in[1 ; n-1], Z_{C k}^{*}<Z_{C k+1}^{*}$. Propositions 4 and 5 may be applied to compare mode $k \in[1 ; n]$ to all the other available modes $j \in[1 ; n]$ (such that $j \neq k) . Z_{k, j}(E)$ is the corresponding efficient frontier (by extension, we also consider $Z_{k, k}(E)=Z_{k}\left(E_{k}\right)$ ). Let define $Z_{k}\left(E_{k}\right)^{\bigcap}=\bigcap_{j=1}^{n} Z_{k, j}(E)$. Note that $Z_{k}\left(E_{k}\right)^{\bigcap}$ may be an empty set. The efficient frontier of the global problem may be identified by applying Proposition 7. 
Proposition 7. Let $Z(E)$ be the set of efficient solutions for the global problem with $n>2$ modes of transportation, then:

$$
Z(E)=\bigcup_{k=1}^{n} Z_{k}\left(E_{k}\right)^{\cap} .
$$

This results enables identifying all the efficient solutions in the case with multiple transportation modes. We provide an example of application in the next section.

\subsection{Example and insights}

We present here an application that illustrates the type of outcome generated by the multiobjective optimization analysis. We decide to focus on a single application as we provide analytical results that enable understanding the behavior of the model for any set of parameters. The application is followed by an illustration of the main insights highlighted in Section 3.2. The application is based on real data in order to ensure the practical relevance of insights.

\subsubsection{Example of the French retailer}

We consider a French retailer who orders bottles of wine from an external supplier. The bottles are delivered on pallets and the retailer has to order an integer amount of pallets. Therefore, we consider that one product unit equals to one pallet. We assume that the assumptions of the EOQ model are fulfilled. We exclude purchase costs and purchase emissions from the analysis as they do not affect the decisions we consider. The data relative to the problem may be found in Table 1.

\begin{tabular}{|c|c|c|}
\hline time unit & 1 & month \\
\hline quantity unit & 1 & pallet \\
\hline unit weight & 500 & $\mathrm{~kg}$ \\
\hline inbound distance & 500 & $\mathrm{~km}$ \\
\hline $\mathrm{D}$ & 20 & pallets/month \\
\hline $\mathrm{hC}_{\mathrm{C}}$ & 75 & euro/pallet.month \\
\hline $\mathrm{h}_{\mathrm{TC}}$ & 50 & euro/pallet.month \\
\hline $\mathrm{O}_{\mathrm{C}}$ & 100 & euro/order \\
\hline $\mathrm{h}_{\mathrm{E}}$ & 2.65 & $\mathrm{~kg} \mathrm{CO} /$ pallet.month \\
\hline
\end{tabular}

Table 1: Application's data

Assume first that the French retailer decides to use heavy duty trucks for inbound transportation. The truck capacity is $Q_{\max }=33$ euro pallets and the transportation leadtime is $L=0.017$ month (i.e., 0.5 day). 
At first, we assume that the truck transportation cost is linear in the order quantity with $T_{V C}=30 €$ per pallet and $T_{F C}=0 €$ per truck (i.e., following a less than truckload tariff) and we consider that the minimum capacity for getting this tariff consists in ordering $Q_{\min }=10$ pallets.

The Network for Transport and Environment methodology (NTM, 2008) is used to evaluate the carbon emissions related to transportation. This methodology developed by a Swedish not-for-profit organization provides estimates for emissions generated by different modes of transportation in Europe. The NTM methodology may be applied at the aggregate level for less than truckload transport by computing a per product amount of carbon emissions by considering a given average load factor. However, VelázquezMartínez et al. (2013) have shown that such aggregate approach may lead to substantial errors as the effects of lot sizing decisions on the load factor are disregarded. The NTM methodology also enables a more detailed estimation of carbon emissions by considering the fixed emissions generated by the truck when running empty and the per pallet emissions due to the extra energy consumption. The detailed model provided by the NTM methodology is used in our application as the load factor depends on the order quantity decision. Indeed, we assume that the retailer does not allow the logistics provider for including other type of cargo for inbound transportation and consequently has a direct control on the load factor. This situation is classical for retail distribution and this explains why the minimum shipment size is 10 pallets. According to the NTM methodology, the fixed carbon emissions are equal to $T_{F E}=324 \mathrm{~kg} \mathrm{CO}_{2}$ for the proposed example. The maximum load of the truck is 26 tons of cargo. The truck is thus fully loaded in volume with 33 pallets for a corresponding load factor of 0.63 in this application. This leads to a variable amount of carbon emissions $T_{V E}=3.69 \mathrm{~kg} \mathrm{CO}_{2}$ per pallet.

The conditions stated in Lemma 1 are satisfied for the example so we can conclude that $Q_{C}^{*} \leq Q_{\max }$. By applying Formula 3 with this example, we obtain that $Q_{C}^{*}=10$ pallets as $\sqrt{\frac{2\left(O_{C}+T_{F C}\right) D}{h_{C}}} \approx 7.3<10$ . By applying Formula 5, we obtain that $Q_{E}^{*}=33$ pallets as $\sqrt{\frac{2 T_{F E} D}{h_{E}}} \approx 70.0>33$. Note that $Q_{C}^{*}<Q_{E}^{*}$ in the example as stated in Section 3.2.1. The results are summarized in Table 2.

\begin{tabular}{|l|cccccccccc|}
\hline & $Q_{\min }$ & $Q_{\max }$ & $T_{F C}$ & $T_{F E}$ & $\sqrt{\frac{2\left(O_{C}+T_{F C}\right) D}{h_{C}}}$ & $\sqrt{\frac{2 T_{F E} D}{h_{E}}}$ & $Q_{C}^{*}$ & $Q_{E}^{*}$ & $Z_{C}^{*}$ & $Z_{E}^{*}$ \\
\hline Truck transportation & 10 & 33 & 0 & 324 & 7.3 & 70.0 & 10.0 & 33.0 & 1191.67 & 313.92 \\
\hline
\end{tabular}

Table 2: Parameters for truck transportation 
By applying Proposition 1, we obtain that $E=[10 ; 33]$. Figure 3 displays the efficient frontier as well as its convex hull. The $\mathrm{x}$-axis corresponds to the costs and the $\mathrm{y}$-axis corresponds to the carbon emissions. Figure 1 shows that $Z(E)$ is convex as stated in Proposition 2. We also include in Figure 3 some dominated solutions obtained when ordering more than a full truckload (dashed line). We can observe that ordering more than a full truckload is not effective as this implies an increase in cost (as stated in Lemma 1) as well as an increase in carbon emissions (as emissions cannot be decreased by ordering more than a full vehicle according to Expression (5)).

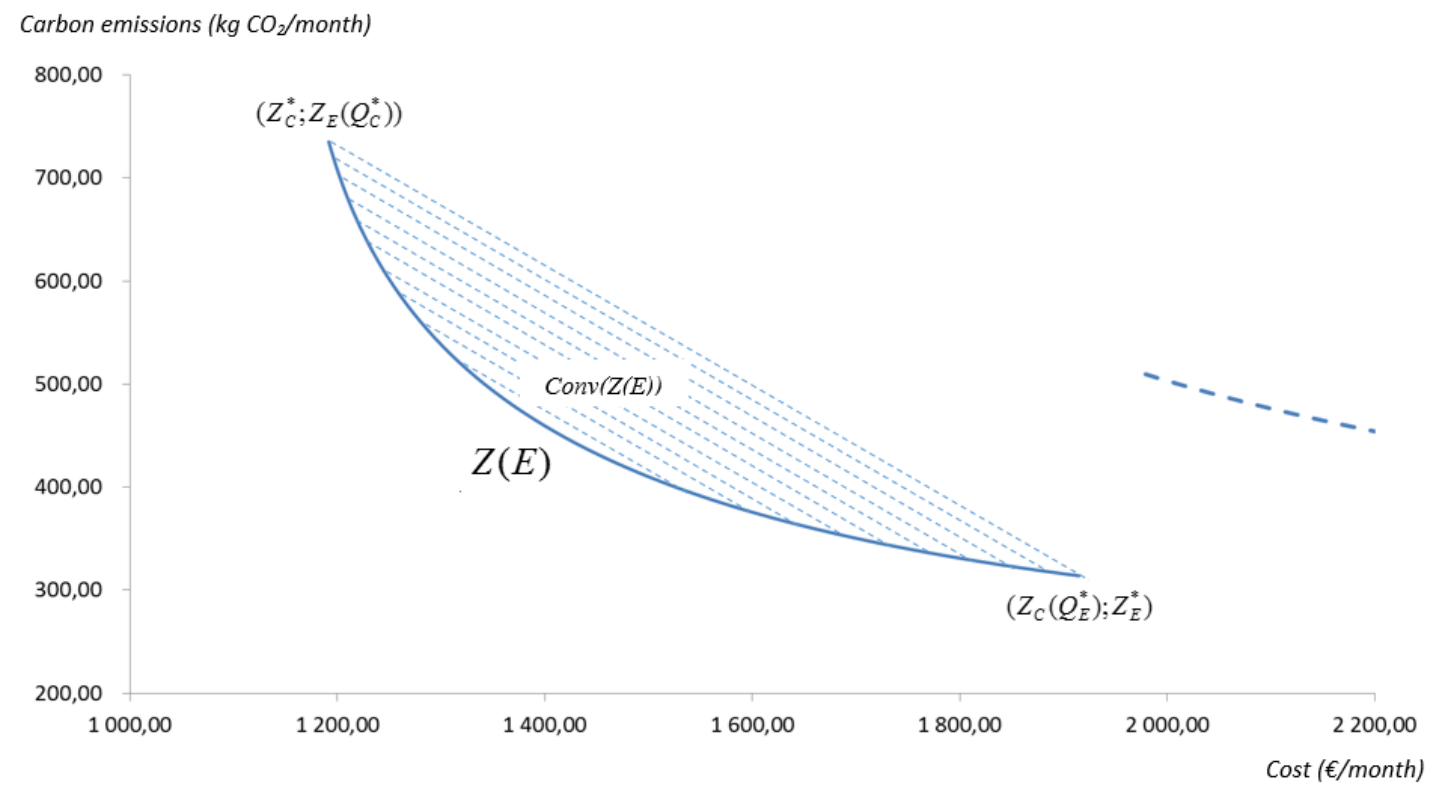

Figure 3: The efficient frontier with a single mode of transportation

Consider now that rail transportation is also available for inbound transportation to the French retailer. A train includes 26 freight cars, each of them fully loaded in volume with 36 pallets. The rail transportation leadtime is 0.067 month (i.e., 2 days). A fixed transportation cost $T_{F C}=449 €$ per freight car is considered. In opposition to truck transportation, several types of cargo (from several retailers) may be included into the same train. In this case, the carbon emissions associated with the train when running empty may be split between the different users. A fixed amount of carbon emissions per freight car is then derived from the average utilization rate of the train. Moreover, a variable amount of carbon emissions is associated to each pallet. By using average values provided by the NTM methodology, we obtain that $T_{F E}=333 \mathrm{~kg}$ $\mathrm{CO}_{2}$ per freight car and $T_{V E}=1.30 \mathrm{~kg} \mathrm{CO}_{2}$ per pallet. Due to both costs and carbon emissions structure, 
there is no incentive to order more than one full freight car. Note that the results of Section 3.1 and 3.2.1 may be applied to train transportation. The results are summarized in Table 3.

\begin{tabular}{|c|cccccccccc|}
\hline & $Q_{\min }$ & $Q_{\max }$ & $T_{F C}$ & $T_{F E}$ & $\sqrt{\frac{2\left(O_{C}+T_{F C}\right) D}{h_{C}}}$ & $\sqrt{\frac{2 T_{F E} D}{h_{E}}}$ & $Q_{C}^{*}$ & $Q_{E}^{*}$ & $Z_{C}^{*}$ & $Z_{E}^{*}$ \\
\hline Train transportation & 1 & 36 & 449 & 333 & 17.1 & 71.0 & 17.1 & 36.0 & 1350.29 & 258.86 \\
\hline
\end{tabular}

Table 3: Parameters for train transportation

From Table 3 and Table 2, we can notice that $Z_{\text {Ctruck }}^{*}<Z_{\text {Ctrain }}^{*}$ and $Z_{\text {Etruck }}^{*}>Z_{\text {Etrain }}^{*}$ thus Proposition 4 can be applied. By solving the system of equations leading to an intersection between $Z_{\text {truck }}\left(E_{\text {truck }}\right)$ and $Z_{\text {train }}\left(E_{\text {train }}\right)$, we obtain that $Z_{\text {truck }}\left(E_{\text {truck }}\right) \cap Z_{\text {train }}\left(E_{\text {train }}\right)=\varnothing$. Moreover, we can notice that $Z_{\text {truck }}\left(Q_{\text {Etruck }}^{*}\right)=\{1914.77 ; 313.92\}$ is dominated by $Z_{\text {train }}\left(Q_{\text {Etrain }}^{*}\right)=\{1721.79 ; 258.86\}$. Then, by applying Proposition 4, we obtain that $Z(E)=\left\{\left(c_{1} ; e_{1}\right) \in Z_{\text {truck }}\left(E_{\text {truck }}\right) \mid c_{1}<Z_{\text {Ctrain }}^{*}\right\} \cup Z_{\text {train }}\left(E_{\text {train }}\right)$. The results are illustrated in Figure 4. We can also notice that the efficient frontier $Z(E)$ is non-continuous thus nonconvex as shown by Proposition 6.

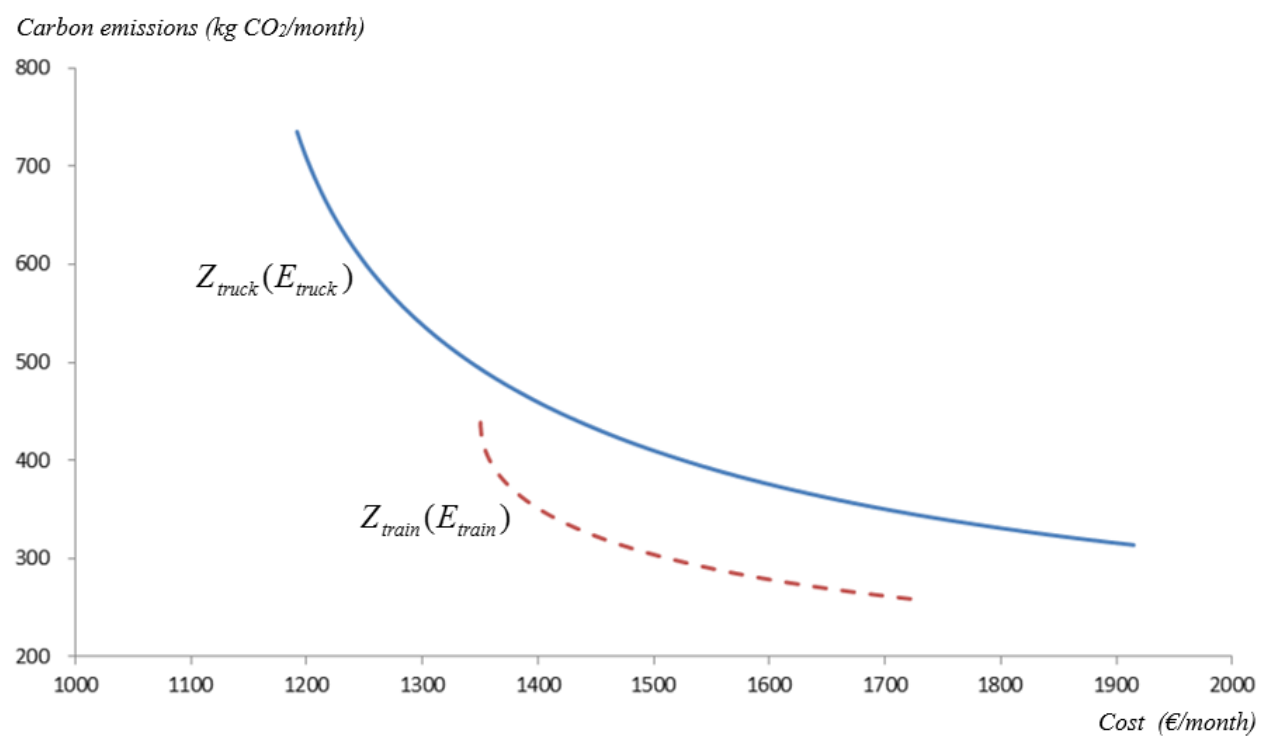

Figure 4: Truck and train transportation efficient frontiers

Finally, assume that the logistics provider offer two additional tariffs for truck transport. One tariff is an all unit discount less than truckload tariff with $T_{V C}=20 €$ per pallet if the quantity ordered is higher or equal to 21 pallets. The second additional tariff is a full truckload tariff with $T_{F C}=600 €$ per truck and 
$T_{V C}=0 €$ per pallet. As noticed in Section 3.1, transportation costs follow a modified all-unit discount structure with one discount rate and one full truckload rate. As stated in Section 3.1, truck transportation is considered in the model as 4 different transportation modes as the cost parameters and minimum quantities differ for each tariff. The global problem consists of deciding between 5 different modes of transport and in deciding on the optimal order quantity. We refer to these modes as mode $i \in[1 ; 5]$. Table 4 provides a synthesis of the main parameters for mode $i \in[1 ; 5]$ as well as the results obtained from Section 3.2.1. Train transportation is referred to as mode 4 as this ensure that for all $k \in[1 ; 4], Z_{C k}^{*}<Z_{C k+1}^{*}$ . When focusing on mode $1, Q_{\max 1}$ is set to 14 pallets as a better tariff (with the same level of carbon emissions) may be obtained with mode 2 when $Q>14$. Figure 5 illustrates the results obtained in Table 4 in the criterion space.

\begin{tabular}{|c|cccccccccc|}
\hline & $Q_{\min }$ & $Q_{\max }$ & $T_{F C}$ & $T_{F E}$ & $\sqrt{\frac{2\left(O_{C}+T_{F C}\right) D}{h_{C}}}$ & $\sqrt{\frac{2 T_{F E} D}{h_{E}}}$ & $Q_{C}^{*}$ & $Q_{E}^{*}$ & $Z_{C}^{*}$ & $Z_{E}^{*}$ \\
\hline mode 1 & 10 & 14 & 0 & 324 & 7.3 & 70.0 & 10.0 & 14.0 & 1191.67 & 555.25 \\
\hline mode 2 & 14 & 21 & 420 & 324 & 16.7 & 70.0 & 16.7 & 21.0 & 1265.67 & 410.24 \\
\hline mode 3 & 21 & 30 & 0 & 324 & 7.3 & 70.0 & 21.0 & 30.0 & 1299.40 & 329.58 \\
\hline mode 4 & 1 & 36 & 449 & 333 & 17.1 & 71.0 & 17.1 & 36.0 & 1350.29 & 258.86 \\
\hline mode 5 & 30 & 33 & 600 & 324 & 19.3 & 70.0 & 30.0 & 33.0 & 1608.33 & 313.92 \\
\hline
\end{tabular}

Table 4: Synthesis of the different modes

The results of Section 3.2.3 are applied to identify the set of efficient solution for the global problem. With 5 different modes, 24 pairwise comparisons are theoretically required, but we can notice that the analysis is totally disjointed for mode 1 and mode 2 and that $Z_{5}\left(E_{5}\right)^{\cap}=\varnothing$ by comparing to mode 4 . The results of Section 3.2.3 boil down to apply the results of Section 3.2.2 to mode 1 and mode 2 and to mode 3 and mode 4 separately. The final results are presented in Figure 6. 


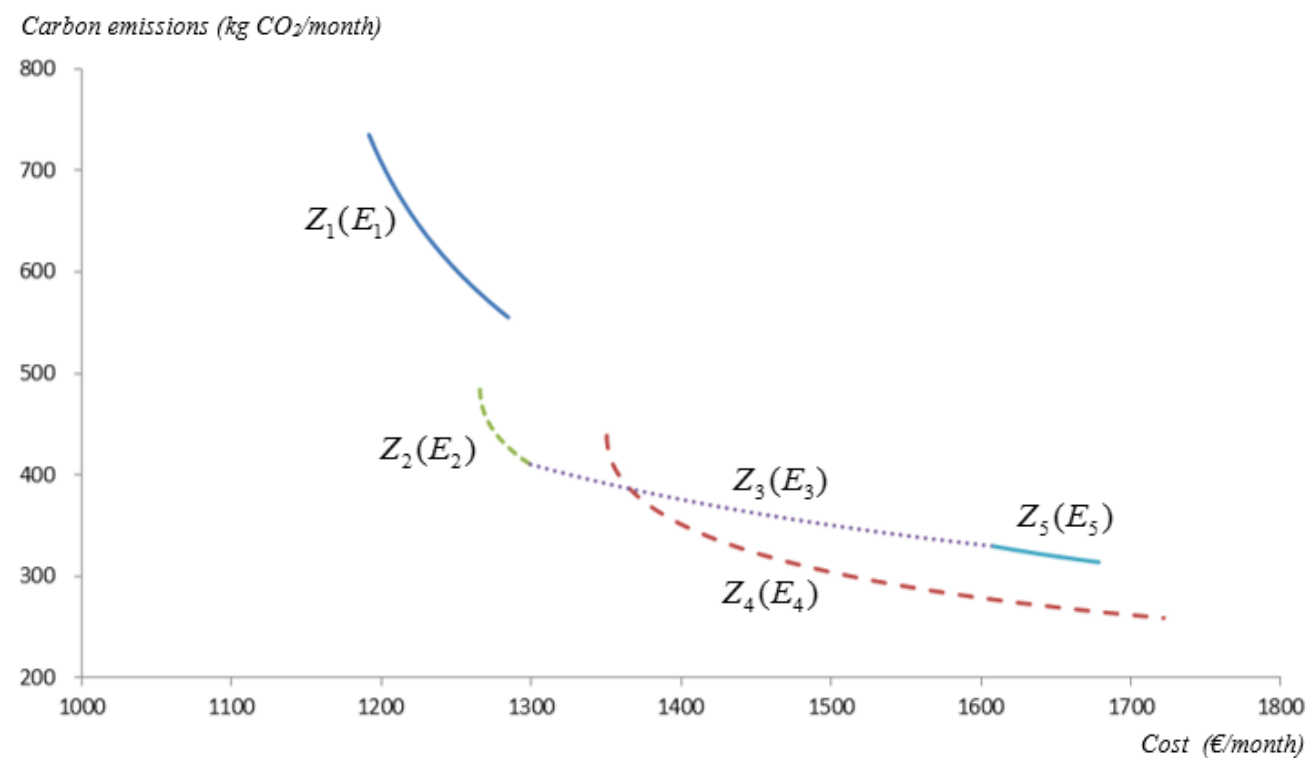

Figure 5: Efficient frontiers for the different modes

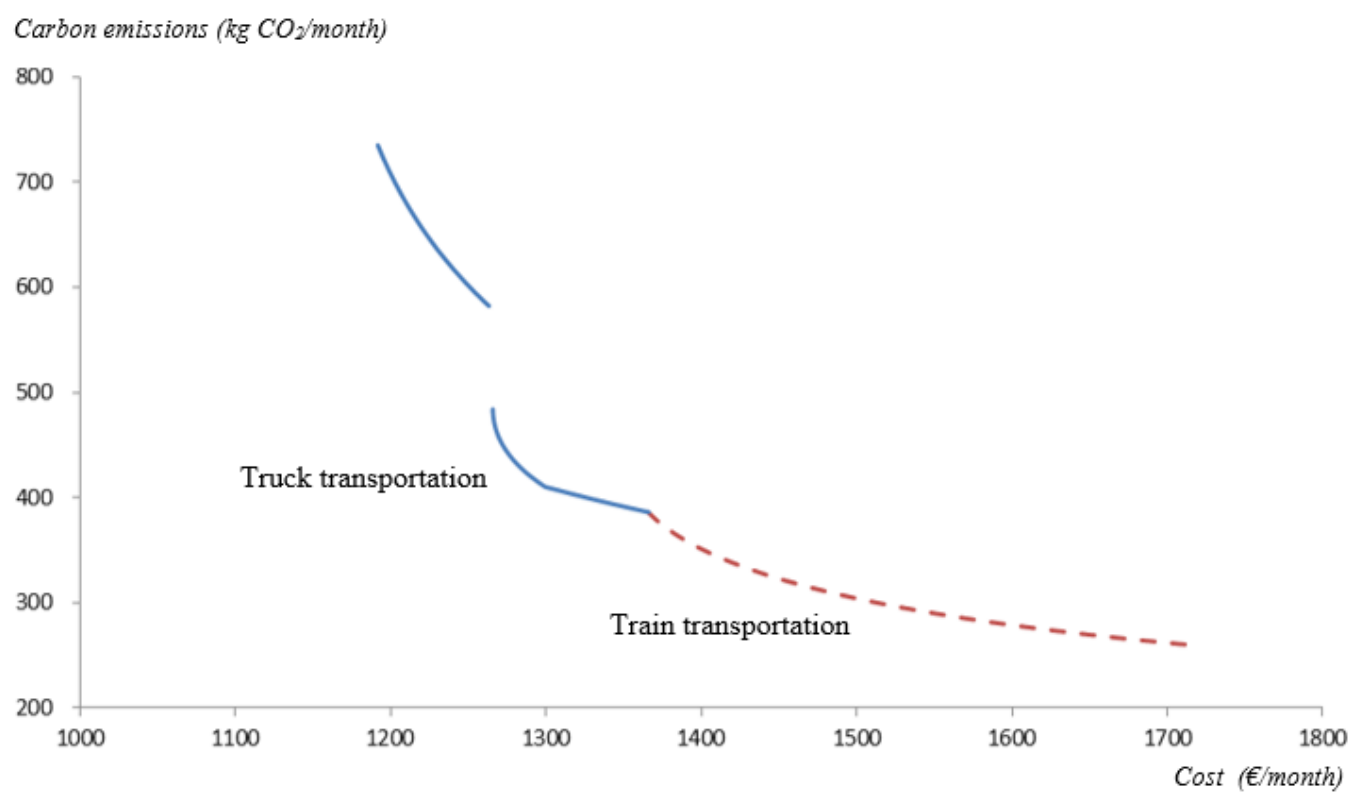

Figure 6: Joint efficient frontier of the different modes

\subsubsection{Insights from multiobjective optimization}

The new multiobjective optimization results applied to the example of the French retailer enables to exemplify the insights highlighted in Section 3.2.2.

First, assume that the retailer currently orders $Q=10$ pallets (i.e. that the retailer minimizes its total logistics costs). Figure 5 shows that a carbon emissions reduction of $57 \%$ can be achieved by increasing 
the order quantity up to 33 pallets without switching to a greener mode of transportation. This feature illustrates that increasing the order quantity (i.e., increasing the load factor for transportation) is very efficient for reducing the supply chain emissions. Moreover, the required financial effort first remains reasonable when decreasing carbon emissions. For instance, choosing truck transportation with $Q=16.7$ enables a $34 \%$ reduction in carbon emissions for a $6 \%$ costs increase. On the opposite, the financial effort will increase as $Q$ is getting closer to the order quantity that minimizes the amount of carbon emissions for truck transportation. This feature is commonly highlighted in the literature on inventory control with carbon emissions concerns (Bouchery et al., 2012; Chen et al., 2013) due to the relative insensitivity of the costs to a variation in the order quantity. We prove here that the results remain valid when explicitly including transportation features into the economic order quantity model. This implies that switching to a greener mode of transportation is efficient only in case of a strong carbon emissions reduction target. For the example proposed, shifting from truck to train becomes interesting if the carbon emissions reduction target is a least $50 \%$ or for a carbon price greater than $1670 € /$ ton $\mathrm{CO}_{2}$ (this result is obtained by identifying the common tangent between truck and train transportation). In other situations, adjusting the order quantity while continuing to use truck transportation would be more efficient to green the supply chain.

The example of the French retailer also illustrates that switching to a greener mode of transportation while continuing to optimize the total logistic cost function may lead to a dominated solution (we refer to Figure 5). Without performing the multiobjective optimization analysis provided in this article, the retailer may decide to switch to rail for inbound transportation while continuing to minimize the total cost function in order to decrease the carbon emissions of the supply chain. This solution leads to $1350 €$ and $441 \mathrm{~kg}$ $\mathrm{CO}_{2}$ per month and may be perceived as appropriate as this leads to a $40 \%$ decrease in carbon emissions for a $13 \%$ increase in costs, when compared to minimizing costs with truck transportation. However, Figure 5 clearly shows that the solution consisting in switching to rail while continuing to minimize the cost function is a dominated solution. The same decrease in carbon emissions may be achieved with a cost reduced by more than $5 \%$ by continuing to use truck for inbound transportation and by choosing $Q=19$ (leading to $1277 €$ and $440 \mathrm{~kg} \mathrm{CO}$ per month). This example clearly shows that switching to a greener mode of transportation while continuing to optimize the cost function may not be the best option to green the supply chain. This highlights the necessity of taking an integrated inventory control and transportation mode selection perspective when intending to green the supply chain. 


\subsection{Cost model with a carbon price}

In this section, we aim at comparing our results to the ones obtained if a price is associated to carbon emissions. We indeed argued that the weighted sum method was not appropriate to generate all the efficient solutions if the efficient frontier is non-convex, and we concluded that carbon pricing might not be a proper way of generating efficient solutions for the problem we consider as we proved that the efficient frontier is not convex in many cases.

We consider that a price is associated to the company's carbon emissions. This price can be imposed to the company in the case of a carbon tax. However, this price can also come from an internal evaluation from the company, by considering the cost of the energy used or the cost obtained with an environmental accounting analysis. This price per amount of carbon emissions is noted $\alpha \in[0 ; \infty)$. We perform the analysis by considering two transportation modes. In this context, there exists a value $L_{C} \in(0 ; \infty)$ that allows deciding which mode is the most interesting as we show in Proposition 8.

Proposition 8. Assume that a price $\alpha$ is associated to the company's carbon emissions and assume that the company can decide between modes 1 and 2 with $Z_{C 1}^{*}<Z_{C 2}^{*}$ and $Z_{E 1}^{*}>Z_{E 2}^{*}$. Then there exists a value $L_{C}$ such that:

$$
\begin{aligned}
& \text { - if } \alpha<L_{C} \text {, then } \min \left(Z_{1}(Q)+\alpha E_{1}(Q)\right)<\min \left(\left(Z_{2}(Q)+\alpha E_{2}(Q)\right)\right. \text {, } \\
& \text { - if } \alpha>L_{C} \text {, then } \min \left(Z_{1}(Q)+\alpha E_{1}(Q)\right)>\min \left(\left(Z_{2}(Q)+\alpha E_{2}(Q)\right)\right. \text {. }
\end{aligned}
$$

The value of $L_{C}$ is unique and may be found by identifying a value $\alpha_{1}$ such that $\min \left(Z_{1}(Q)+\alpha_{1} E_{1}(Q)\right)>\min \left(\left(Z_{2}(Q)+\alpha_{1} E_{2}(Q)\right)\right.$ (i.e. $\left.\alpha_{1}>L_{C}\right)$ and by applying the bisection method on the interval $\left[0 ; \alpha_{1}\right]$ (at each iteration, we select the interval $\left[\alpha_{i} ; \alpha_{i+1}\right]$ such that $\min \left(Z_{1}(Q)+\alpha_{i} E_{1}(Q)\right)<\min \left(\left(Z_{2}(Q)+\alpha_{i} E_{2}(Q)\right)\right.$ and $\min \left(Z_{1}(Q)+\alpha_{i+1} E_{1}(Q)\right)>\min \left(\left(Z_{2}(Q)+\alpha_{i+1} E_{2}(Q)\right)\right)$. We apply the method to the example proposed in Figure 4 and we illustrate the results in Figure 7 . The common tangent as well as the efficient solutions not identified by the weighted sum approached (the nonsupported efficient solutions) are displayed (dashed lines) in addition to the efficient solutions obtained with the weighted sum method. 


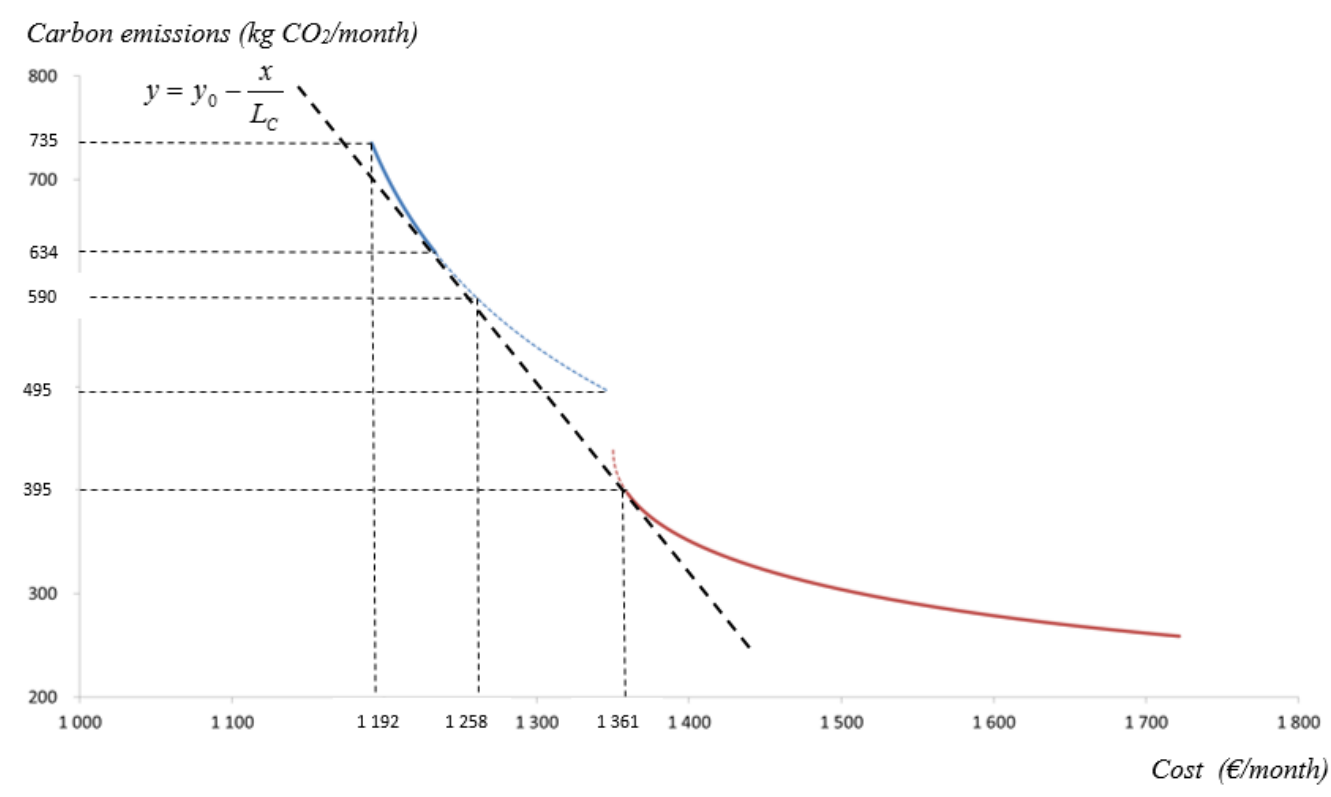

Figure 7: The efficient frontier obtained with the weighted sum method

Figure 7 clearly highlights that the weighted sum approach is not appropriate for identifying all the efficient solutions of the problem. This could provide misleading impression to the decision maker. For instance, the decision maker could conclude that the maximum reduction in carbon emissions achievable by efficiently using truck transport is $14 \%$ (from $735 \mathrm{~kg} \mathrm{CO}_{2}$ per month to $634 \mathrm{~kg} \mathrm{CO}_{2}$ per month), instead of $33 \%$ (from $735 \mathrm{~kg} \mathrm{CO}_{2}$ per month to $495 \mathrm{~kg} \mathrm{CO}_{2}$ per month), if we include the non-supported efficient solutions. In addition, the emissions may be reduced by $20 \%$ (from $735 \mathrm{~kg} \mathrm{CO}_{2}$ per month to $590 \mathrm{~kg} \mathrm{CO} 2$ per month), for an increase in cost of $6 \%$ (from $1192 €$ per month to $1258 €$ per month) if we include the non-supported solutions. In opposite, the cost has to be increased by $14 \%$ (from $1192 €$ per month to $1361 €$ per month) to reduce the emissions by at least $20 \%$ if we ignore the non-supported solutions.

Moreover, a marginal change in carbon price around $L_{C}$ would have a huge effect on the amount of carbon emissions generated. Assume that $\alpha$ raises from $L_{C}-\varepsilon$ to $L_{C}+\varepsilon$ with $\varepsilon$ being arbitrarily small. Then, the optimal level of carbon emissions for the example presented above would drop from $634 \mathrm{~kg} \mathrm{CO}_{2}$ per month to $395 \mathrm{~kg} \mathrm{CO}_{2}$ per month (i.e., $38 \%$ reduction). This implies that a small change in carbon price may have huge impact on carbon emissions.

The case with $\alpha=L_{C}$ is also very interesting. In this case, both transportation modes give the same overall result (operational costs + carbon tax). However, the costs and the carbon emissions are different for both options. In the example highlighted above, when $\alpha=0.542$, using truck would lead to $1231+0.542 * 634=1575 €$ per month while using train would lead to $1361+0.542 * 395=1575 €$ per month. 
Consequently, the company may decide among the two options. This operational flexibility implies that the total amount of carbon emissions is hardly controllable by setting a carbon price as the amount of carbon emissions for a given carbon price is not necessarily unique and may widely differ. We provide additional insights on the impact of vehicle capacity in the next section.

\subsection{Impact of vehicle capacity}

Vehicle capacity is often limited by regulation. For instance, the maximum length of a truck in France is limited to 18.25 meters (33 euro pallets) while the maximum weight eligible for truck transportation is 26 tons of goods. Logistics providers often argue that increasing vehicle capacities could strongly impact the performance of deliveries both in terms of costs and carbon emissions. In this section, we intend to analyze the impact of increasing trucks capacity in France, based on our results and on the example we provide in Section 3.3. Most of the existing studies on this topic only focus on transportation and only compare the performances of existing trucks with the performances of longer trucks. Our results enable a more extensive study by including the effects of the variation in inventory and by also comparing to a shift to train.

We focus on the impact of allowing European Modular System (EMS) in France. EMS consists of combining existing loading units to form a longer truck. These longer trucks are currently tested in many European countries with good results in terms of carbon emissions. An EMS truck can be up to 25.25 meters long and carries up to 52 pallets. We investigate the impact of allowing for EMS trucks in France by using the example presented in Section 3.3. We assume that the trucks can now be loaded with 52 pallets and that the full truckload tariff does not change (i.e., $T_{F C}=600 €$ per truck). We also take the optimistic assumption that the emissions due to empty running are similar to a conventional heavy duty truck, i.e., $T_{F E}=324 \mathrm{~kg} \mathrm{CO}_{2}$. Finally, we assume that the variable emissions from transportation remain unchanged, i.e., $T_{V E}=3.69 \mathrm{~kg} \mathrm{CO}_{2}$ per pallet. The results we obtain in this case are shown in Figure 8.

Figure 8 highlights that the increase in truck capacity does not affect the results. Indeed, the new solutions available are dominated by train transportation. This may be explained as follows by comparing the results obtained when 52 pallets are transported with an EMS truck with the results obtained when 36 pallets are transported by rail. EMS trucks perform better than rail transport both in terms of costs and emissions for the example we propose. Indeed, transportation costs (respectively emissions) equal $247 €$ per month (respectively $200 \mathrm{~kg} \mathrm{CO}_{2}$ per month) with a full EMS truck as compared to $316 €$ per month (respectively $211 \mathrm{~kg} \mathrm{CO} 2$ per month) for a full freight car. However, inventory holding costs equal to $1950 €$ per month if the order quantity is 52 pallets, instead of $1350 €$ per month if the order quantity is 
36 pallets. This explains why extending the truck capacity is not efficient from a cost perspective for the example we consider. Similarly, inventory holding emissions raise from $48 \mathrm{~kg} \mathrm{CO}_{2}$ per month to $69 \mathrm{~kg} \mathrm{CO} 2$ per month when increasing the order quantity from 36 to 52 pallets. This increase is larger than the difference in transportation emissions.

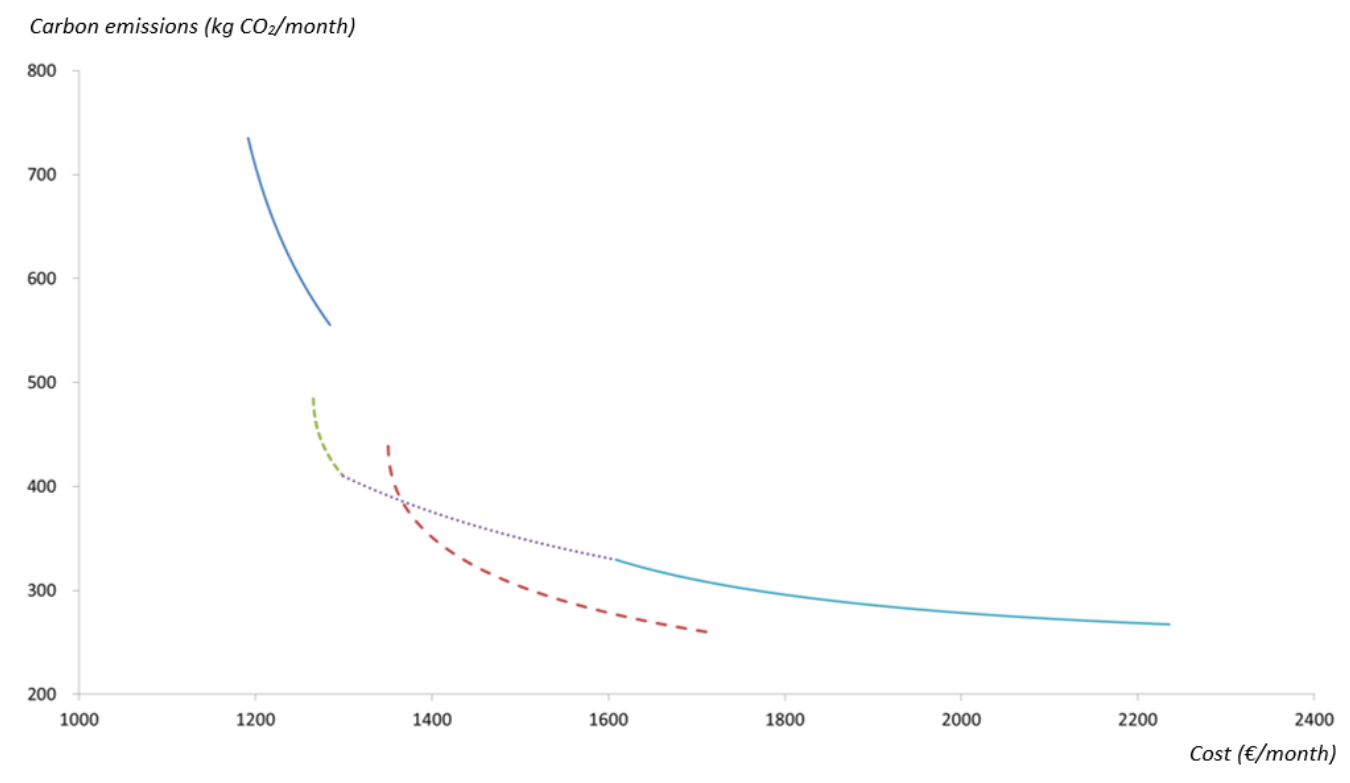

Figure 8: Impact of vehicle capacity

This example enables us to derive the following insights. First, we can notice that when focusing solely on transportation, increasing the truck capacity in Europe may be viewed as very effective. Indeed, if we increase truck capacity from 33 to 52 pallets in the example we consider, transportation costs decrease from $380 €$ per month to $247 €$ per month (35\% decrease in cost) and transportation emissions decrease from $270 \mathrm{~kg} \mathrm{CO}_{2}$ per month to $200 \mathrm{~kg} \mathrm{CO}_{2}$ per month (26\% decrease in emissions). These results also highlight that truck can compete with train in terms of carbon emissions if truck capacity is appropriately extended.

Second, we have highlighted that the increase in inventory while loading 52 pallets in an EMS truck was detrimental both in terms of costs and emissions for the example studied. We conclude that using EMS trucks can be competitive only for a limited set of products (with very low inventory holding cost and emissions) except if several loads can be combined into a single shipment. 


\section{Conclusions}

This article applies multiobjective optimization to show how the efficient tradeoffs between different types of objectives may be obtained in the context of sustainable operations. The article focuses on joint inventory and transportation model with cost and carbon emissions objectives. We prove that switching to a greener mode of transportation while continuing to optimize the total logistics costs function may lead to a dominated solution. The proposed results give additional flexibility to supply chain managers who are likely to be focused on low-carbon transportation projects implementation without taking a total supply chain costs and carbon emissions perspective. We also prove that the modal shift is interesting only for strong carbon emissions reduction requirements. In the provided example base on industrial data, the modal shift is interesting for a 50\% carbon emissions reduction target or for a carbon price greater than $1670 € /$ ton $\mathrm{CO}_{2}$. On other situations, adjusting the order quantity while continuing to use truck transportation would be more efficient to green the supply chain. We also highlight the drawbacks of using carbon pricing to account for carbon emissions and we investigate the impact of an increase in vehicle capacity.

Several research directions can be considered. First, other models related to sustainable operations

could be revisited by using multiobjective optimization. Multiobjective optimization could indeed be efficiently used as a first step of analysis in order to provide an effective decision making support tool to the decision maker by enabling a graphical representation of the existing tradeoffs. The decision maker may thus easily build a conviction of what is possible and use this knowledge to identify the most valuable trade-off. Moreover, this process of simultaneously optimizing several conflicting objectives adequately reflects the concept of sustainable operations as the different dimensions of sustainability are a good illustration of multiple objectives.

Second, other transportation mode selection and inventory optimization models could be studied. For instance, considering both stochastic demand and stochastic transportation lead times may enable enriching the analysis. In this case, safety stock optimization decisions has to be considered in addition to transportation mode selection and order quantity optimization decisions. Note that Konur and Schaefer (2015) paved the way for such type of study. More complex supply chain structures could also be considered by revisiting the multi-echelon lot sizing models. Considering a carbon-sensitive demand could also be of great interest as customers' pressure is nowadays considered as a main driver of environmental improvements for companies. 
Third, other dimensions of sustainability could also be considered in order to take a broader sustainable operations perspective. For instance, very interesting analyses may be developed by taking the impact of working conditions into account such as the level of training into operations management models. Other people related dimensions of sustainable operations such as the risk of accident resulting in injuries or deaths may also be included into the models. This research direction may however be viewed as challenging as there is still a lack of consensus on how to assess the social dimension of sustainable operations.

\section{Acknowledgements}

The authors would like to thank the editor as well as two anonymous referees for their valuable comments and suggestions.

\section{Appendix A}

\section{Proof of Lemma 1:}

According to Expression (2), $Z_{C}(Q)=Z_{C}^{\prime}(Q)+T_{C}(Q) \frac{D}{Q}$ with $Z_{C}^{\prime}(Q)=O_{C} \frac{D}{Q}+h_{C} \frac{Q}{2}+P_{C} D . Z_{C}^{\prime}$ is convex in $Q$ and its minimum is obtained for $Q^{\prime *}=\sqrt{\frac{2 O_{C} D}{h_{C}}}$. Let $O_{C} \leq \frac{h_{C} Q_{\max }^{2}}{2 D}$, then $Q^{\prime *} \leq Q_{\max }$ and we obtain that for all $Q>Q_{\max }, \quad Z_{C}^{\prime}(Q)>Z_{C}^{\prime}\left(Q_{\max }\right)$. In addition, for all $Q>Q_{\max }$, $T_{C}(Q) \frac{D}{Q} \geq T_{C}\left(Q_{\max }\right) \frac{D}{Q_{\max }}$. We conclude that for all $Q>Q_{\max }, Z_{C}(Q)>Z_{C}\left(Q_{\max }\right)$ thus $Q^{*} \leq Q_{\max }$. This concludes the proof.

\section{Proof of Proposition 1:}

Both $Z_{C}(Q)$ and $Z_{E}(Q)$ are convex on $\left[Q_{\min } ; Q_{\max }\right]$. If $Q_{C}^{*}=Q_{E}^{*}, E=Q_{C}^{*}$ as $Q_{C}^{*}$ is the optimal order quantity for both costs and carbon emissions. Assume that $Q_{C}^{*}<Q_{E}^{*}$, then $Z_{C}(Q)$ is strictly increasing on $\left[Q_{C}^{*}, Q_{E}^{*}\right], Z_{E}(Q)$ is strictly decreasing on $\left[Q_{C}^{*}, Q_{E}^{*}\right]$, and both $Z_{C}(Q)$ and $Z_{E}(Q)$ are strictly increasing on $\left[Q_{E}^{*}, Q_{\max }\right]$ and strictly decreasing on $\left[Q_{\min }, Q_{C}^{*}\right]$. Any solution $Q \notin\left[Q_{C}^{*}, Q_{E}^{*}\right]$ is then dominated. By using the same argumentation as for $Q_{E}^{*}<Q_{C}^{*}$, it follows that: $E=\left[\min \left(Q_{C}^{*}, Q_{E}^{*}\right) ; \max \left(Q_{C}^{*}, Q_{E}^{*}\right)\right]$. This concludes the proof. 


\section{Proof of Proposition 2:}

Let $\{c, e\}$ be an element of $\operatorname{Conv}(Z(E))$. $\{c, e\}$ can be expressed as the barycenter of at most three elements of $Z(E)$ by using Caratheodory's theorem, thus there exists $\left\{Q_{1} ; Q_{2} ; Q_{3}\right\} \in E^{3}$ such that:

$\{c, e\}=\left\{\lambda_{1} Z_{C}\left(Q_{1}\right)+\lambda_{2} Z_{C}\left(Q_{2}\right)+\lambda_{3} Z_{C}\left(Q_{3}\right) ; \lambda_{1} Z_{E}\left(Q_{1}\right)+\lambda_{2} Z_{E}\left(Q_{2}\right)+\lambda_{3} Z_{E}\left(Q_{3}\right)\right\} \quad$ with $\sum_{i=1}^{3} \lambda_{i}=1$. As $Z_{C}(Q)$ and $Z_{E}(Q)$ are convex on $E$, we obtain that $c \geq Z_{C}\left(\lambda_{1} Q_{1}+\lambda_{2} Q_{2}+\lambda_{3} Q_{3}\right)$ and $e \geq Z_{E}\left(\lambda_{1} Q_{1}+\lambda_{2} Q_{2}+\lambda_{3} Q_{3}\right)$. Moreover, the equalities hold only if $\{c, e\} \in Z(E)$. We conclude that $\operatorname{Eff}(\operatorname{Conv}(Z(E)))=Z(E)$ as $\lambda_{1} Q_{1}+\lambda_{2} Q_{2}+\lambda_{3} Q_{3} \in E$. This concludes the proof.

\section{Proof of Proposition 3:}

Let $\{c, e\}$ be an element of $Z_{1}\left(E_{1}\right) \cap Z_{2}\left(E_{2}\right)$. Then there exists $\left\{Q_{1} ; Q_{2}\right\} \in E_{1} \times E_{2}$ such that $c=Z_{C 1}\left(Q_{1}\right)=Z_{C 2}\left(Q_{2}\right)$ and $e=Z_{E 1}\left(Q_{1}\right)=Z_{E 2}\left(Q_{2}\right)$. These conditions are equivalent to:

$$
\begin{gathered}
\left\{\begin{array} { l } 
{ Z _ { C 1 } ( Q _ { 1 } ) = Z _ { C 2 } ( Q _ { 2 } ) } \\
{ Z _ { E 1 } ( Q _ { 1 } ) = Z _ { E 2 } ( Q _ { 2 } ) }
\end{array} \Leftrightarrow \left\{\begin{array}{l}
\frac{h_{C}}{2 D}\left(Q_{1}-Q_{2}\right)=\frac{O_{C}+T_{F C 2}}{Q_{2}}-\frac{O_{C}+T_{F C 1}}{Q_{1}}+h_{T C}\left(L_{2}-L_{1}\right)+T_{V C 2}-T_{V C 1} \\
\frac{h_{E}}{2 D}\left(Q_{1}-Q_{2}\right)=\frac{T_{F E 2}}{Q_{2}}-\frac{T_{F E 1}}{Q_{1}}+T_{V E 2}-T_{V E 1}
\end{array}\right.\right. \\
\Rightarrow h_{E}\left(\frac{O_{C}+T_{F C 2}}{Q_{2}}-\frac{O_{C}+T_{F C 1}}{Q_{1}}+h_{T C}\left(L_{2}-L_{1}\right)+T_{V C 2}-T_{V C 1}\right)=h_{C}\left(\frac{T_{E 2}}{Q_{2}}-\frac{T_{E 1}}{Q_{1}}+T_{V E 2}-T_{V E 1}\right) \\
\Rightarrow \frac{A}{Q_{2}}+\frac{B}{Q_{1}}=C,
\end{gathered}
$$

with:

$$
\begin{aligned}
& A=\frac{h_{E}\left(O_{C}+T_{F C 2}\right)-h_{C} T_{F E 2}}{h_{C} h_{E}}, \\
& B=\frac{h_{C} T_{F E 1}-h_{E}\left(O_{C}+T_{F C 1}\right)}{h_{C} h_{E}}, \\
& C=\frac{h_{T C}\left(L_{1}-L_{2}\right)+T_{V C 1}-T_{V C 2}}{h_{C}}+\frac{T_{V E 2}-T_{V E 1}}{h_{E}} .
\end{aligned}
$$

As $\frac{O_{C}+T_{F C 1}}{h_{C}}<\frac{T_{F E 1}}{h_{E}}$ and $\frac{O_{C}+T_{F C 2}}{h_{C}}<\frac{T_{F E 2}}{h_{E}}$, we obtain that $A<0$ and $B>0$.

If $C=0, Q_{1}=-\frac{B}{A} Q_{2}$. By substituting, we obtain that:

$$
\begin{gathered}
\frac{h_{E}}{2 D}\left(-\frac{B}{A} Q_{2}-Q_{2}\right)=\frac{T_{F E 2}}{Q_{2}}+\frac{A}{B} \frac{T_{F E 1}}{Q_{2}}+T_{V E 2}-T_{V E 1} \\
\Rightarrow P\left(Q_{2}\right)=\frac{h_{E}}{2 D}\left(\frac{B}{A}+1\right) Q_{2}^{2}+\left(T_{V E 2}-T_{V E 1}\right) Q_{2}+T_{F E 2}+\frac{A}{B} T_{F E 1} .
\end{gathered}
$$


Then $P\left(Q_{2}\right)$ is a second degree polynomial that has at most two roots, thus $\left|Z_{1}\left(E_{1}\right) \cap Z_{2}\left(E_{2}\right)\right| \leq 2$. If $C \neq 0$, then:

$$
\begin{gathered}
Q_{1}=\frac{B Q_{2}}{C Q_{2}-A}>0=>Q_{2}>\frac{A}{C}, \\
Q_{2}=\frac{A Q_{1}}{C Q_{1}-B}>0=>Q_{1}<\frac{B}{C} .
\end{gathered}
$$

If $C<0$, then $\frac{B}{C}<0$ and $\left|Z_{1}\left(E_{1}\right) \cap Z_{2}\left(E_{2}\right)\right|=0$.

Assume now that $C>0$. By taking $Q_{1}=\frac{B Q_{2}}{C Q_{2}-A}$, we obtain that:

$$
\begin{gathered}
\frac{h_{E}}{2 D}\left(\frac{B Q_{2}}{C Q_{2}-A}-Q_{2}\right)=\frac{T_{F E 2}}{Q_{2}}-\frac{T_{F E 1}\left(C Q_{2}-A\right)}{B Q_{2}}+T_{V E 2}-T_{V E 1} \\
\Rightarrow P_{1}\left(Q_{2}\right)=\alpha \cdot Q_{2}^{3}+\beta \cdot Q_{2}^{2}+\gamma \cdot Q_{2}+\delta,
\end{gathered}
$$

with:

$$
\begin{aligned}
& \alpha=-\frac{h_{E} C}{2 D}<0, \\
& \beta=\frac{h_{E}}{2 D}(A+B)+\frac{T_{F E 1} C^{2}}{B}+\left(T_{V E 1}-T_{V E 2}\right) C, \\
& \gamma=A\left(T_{V E 2}-T_{V E 1}\right)-\frac{2 T_{F E 1} A C}{B}-T_{F E 2} C, \\
& \delta=A T_{F E 2}+\frac{A^{2} T_{F E 1}}{B} .
\end{aligned}
$$

If $\delta \leq 0$ then $P_{1}(0) \leq 0$ and $P_{1}\left(Q_{2}\right)$ has at least non-positive root as $P_{1}\left(Q_{2}\right)$ tends to $\infty$ as $Q_{2}$ tends to $-\infty(\alpha<0)$. Therefore, $P_{1}\left(Q_{2}\right)$ has at most two strictly positive roots, thus $\left|Z_{1}\left(E_{1}\right) \cap Z_{2}\left(E_{2}\right)\right| \leq 2$.

Assume now that $\delta>0$ :

We start proving that $\delta>0=>\geq 0$.

$$
\delta>0=>A\left(T_{F E 2}+\frac{A T_{F E 1}}{B}\right)>0=>T_{F E 2}+\frac{A T_{F E 1}}{B}<0 .
$$

If $T_{V E 1}-T_{V E 2} \leq 0$ then we obtain that $\gamma \geq 0$. Else, $\frac{h_{T C}\left(L_{1}-L_{2}\right)+T_{V C 1}-T_{V C 2}}{h_{C}}>0$ as $C>0$. In addition, we can see that $B<\frac{T_{F E 1}}{h_{E}}$.

$$
B<\frac{T_{F E 1}}{h_{E}}=>T_{V E 2}-T_{V E 1}-\frac{T_{F E 1} C}{B}<T_{V E 2}-T_{V E 1}-h_{E} C=>T_{V E 2}-T_{V E 1}-\frac{T_{F E 1} C}{B}<-h_{E} \frac{h_{T C}\left(L_{1}-L_{2}\right)+T_{V C 1}-T_{V C 2}}{h_{C}}<0 \text { and }
$$

we obtain that $\gamma \geq 0$.

$\frac{\partial P_{1}\left(Q_{2}\right)}{\partial Q_{2}}=3 \alpha Q_{2}^{2}+2 \beta Q_{2}+\gamma$. Let $\Delta$ be the discriminant of $\frac{\partial P_{1}\left(Q_{2}\right)}{\partial Q_{2}}$, then $\Delta=4 \beta^{2}-12 \alpha \gamma$. 
If $\Delta \leq 0$, then $\frac{\partial P_{1}\left(Q_{2}\right)}{\partial Q_{2}}$ has at most one root. In this case, the sign of $\frac{\partial P_{1}\left(Q_{2}\right)}{\partial Q_{2}}$ changes at most once, then $P_{1}\left(Q_{2}\right)$ has at most two roots and we can conclude that $\left|Z_{1}\left(E_{1}\right) \cap Z_{2}\left(E_{2}\right)\right| \leq 2$.

If $\Delta>0$, the two roots of $\frac{\partial P_{1}\left(Q_{2}\right)}{\partial Q_{2}}$ are $q_{1}=\frac{-2 \beta-\sqrt{\Delta}}{6 \alpha}$ and $q_{2}=\frac{-2 \beta+\sqrt{\Delta}}{6 \alpha}$. $\gamma \geq 0=>\sqrt{\Delta} \geq 2|\beta|$ thus $q_{2}=\frac{-2 \beta+\sqrt{\Delta}}{6 \alpha} \leq 0$. As the sign of $\frac{\partial P_{1}\left(Q_{2}\right)}{\partial Q_{2}}$ changes at most once on $\mathfrak{R}_{+}^{*}$, then $P_{1}\left(Q_{2}\right)$ has at most two strictly positive roots and we can conclude that $\left|Z_{1}\left(E_{1}\right) \cap Z_{2}\left(E_{2}\right)\right| \leq 2$. This concludes the proof.

\section{Proof of Lemma 2:}

Recall that $Z_{C 1}^{*}<Z_{C 2}^{*}$. If $Z_{E 1}^{*}>Z_{E 2}^{*}$, then the number of intersections between $Z_{1}\left(E_{1}\right)$ and $Z_{2}\left(E_{2}\right)$ is an odd number. As $\left|Z_{1}\left(E_{1}\right) \cap Z_{2}\left(E_{2}\right)\right| \leq 2$ by applying Proposition 3, then $\left|Z_{1}\left(E_{1}\right) \cap Z_{2}\left(E_{2}\right)\right| \leq 1$. If $Z_{E 1}^{*} \leq Z_{E 2}^{*}$, then the number of intersections between $Z_{1}\left(E_{1}\right)$ and $Z_{2}\left(E_{2}\right)$ is an even number. As $\left|Z_{1}\left(E_{1}\right) \cap Z_{2}\left(E_{2}\right)\right| \leq 2$ by applying Proposition 3, then $\left|Z_{1}\left(E_{1}\right) \cap Z_{2}\left(E_{2}\right)\right| \in\{0 ; 2\}$. This concludes the proof.

\section{Proof of Proposition 4:}

As $Z_{E 1}^{*}>Z_{E 2}^{*}$, then $\left|Z_{1}\left(E_{1}\right) \cap Z_{2}\left(E_{2}\right)\right| \leq 1$ by applying Lemma 2 .

If $Z_{1}\left(E_{1}\right) \cap Z_{2}\left(E_{2}\right)=\left\{c_{\cap} ; e_{\cap}\right\}$ :

$Z_{1}\left(Q_{C 1}^{*}\right)$ is efficient. Moreover, both $Z_{1}\left(E_{1}\right)$ and $Z_{2}\left(E_{2}\right)$ are continuous by applying Proposition 2 . This implies that all the elements $\left(c_{1} ; e_{1}\right) \in Z_{1}\left(E_{1}\right)$ with $c_{1} \leq c_{\cap}$ are efficient and that all the elements $\left(c_{2} ; e_{2}\right) \in Z_{2}\left(E_{2}\right)$ with $e_{2}>e_{\cap}$ are dominated. As $Z_{2}\left(Q_{E 2}^{*}\right)$ is efficient, we conclude that all the elements $\left(c_{1} ; e_{1}\right) \in Z_{1}\left(E_{1}\right)$ with $c_{1}>c_{\cap}$ are dominated and that all the elements $\left(c_{2} ; e_{2}\right) \in Z_{2}\left(E_{2}\right)$ with $e_{2} \leq e_{\cap}$ are efficient. We conclude that $Z(E)=\left\{\left(c_{1} ; e_{1}\right) \in Z_{1}\left(E_{1}\right) \mid c_{1} \leq c_{\cap}\right\} \cup\left\{\left(c_{2} ; e_{2}\right) \in Z_{2}\left(E_{2}\right) \mid e_{2} \leq e_{\cap}\right\}$.

Else $Z_{1}\left(E_{1}\right) \cap Z_{2}\left(E_{2}\right)=\varnothing$ :

If $Z_{1}\left(Q_{E 1}^{*}\right) \subset Z(E)$ (Figures $2 \mathrm{~b}$ and $2 \mathrm{c}$ ), then all the element of $Z_{1}\left(E_{1}\right)$ are efficient. Moreover, the only efficient solutions of $Z_{2}\left(E_{2}\right)$ are the ones with lower carbon emissions thus $Z(E)=Z_{1}\left(E_{1}\right) \cup\left\{\left(c_{2} ; e_{2}\right) \in Z_{2}\left(E_{2}\right) \mid e_{2}<Z_{E 1}^{*}\right\}$. 
Else (Figures 2d) all the elements of $Z_{2}\left(E_{2}\right)$ are efficient and the only efficient solutions of $Z_{1}\left(E_{1}\right)$ are the ones with lower costs thus $Z(E)=\left\{\left(c_{1} ; e_{1}\right) \in Z_{1}\left(E_{1}\right) \mid c_{1}<Z_{C 2}^{*}\right\} \cup Z_{2}\left(E_{2}\right)$. This concludes the proof.

\section{Proof of Proposition 5:}

As $Z_{E 1}^{*}<Z_{E 2}^{*}$, then $\left|Z_{1}\left(E_{1}\right) \cap Z_{2}\left(E_{2}\right)\right| \in\{0 ; 2\}$ by applying Lemma 2 . If $Z_{1}\left(E_{1}\right) \cap Z_{2}\left(E_{2}\right)=\varnothing$, then either all the elements of $Z_{2}\left(E_{2}\right)$ are efficient or all of them are dominated by elements of $Z_{1}\left(E_{1}\right)$ by using the same arguments as for Proposition 4. If $Z_{2}\left(Q_{C 2}^{*}\right)$ is efficient then $Z(E)=\left\{\left(c_{1} ; e_{1}\right) \in Z_{1}\left(E_{1}\right) \mid c_{1}<Z_{C 2}^{*}\right\}$ $\cup Z_{2}\left(E_{2}\right) \cup\left\{\left(c_{1} ; e_{1}\right) \in Z_{1}\left(E_{1}\right) \mid e_{1}<Z_{E 2}^{*}\right\}$, else $Z(E)=Z_{1}\left(E_{1}\right) . \quad$ If $\quad, \quad Z_{1}\left(E_{1}\right) \cap Z_{2}\left(E_{2}\right) \neq \varnothing \quad$, then $Z_{1}\left(E_{1}\right) \cap Z_{2}\left(E_{2}\right)=\left\{c_{\cap 1} ; e_{\cap 1}\right\} \cup\left\{c_{\cap 2} ; e_{\cap 2}\right\}$ with $e_{\cap 2}<e_{\cap 1}$. By using the same arguments as for Proposition 4, we conclude that:

$Z(E)=\left\{\left(c_{1} ; e_{1}\right) \in Z_{1}\left(E_{1}\right) \mid e_{1} \geq e_{\cap 1}\right.$ or $\left.e_{1} \leq e_{\cap 2}\right\} \cup\left\{\left(c_{2} ; e_{2}\right) \in Z_{2}\left(E_{2}\right) \mid e_{\cap 2} \leq e_{2} \leq e_{\cap 1}\right\}$. This concludes the proof.

\section{Proof of Proposition 6:}

If $Z(E)=Z_{1}\left(E_{1}\right)$ then $Z(E)$ is convex by applying Proposition 2. If $Z_{1}\left(E_{1}\right) \cap Z_{2}\left(E_{2}\right)=\emptyset$, then $Z(E)$ is non-continuous thus non-convex. Otherwise, assume that $\left\{c_{\cap} ; e_{\cap}\right\}$ is the element of $Z_{1}\left(E_{1}\right) \cap Z_{2}\left(E_{2}\right)$ with the biggest evaluation in terms of carbon emissions. Let $\varepsilon$ be a small positive number. Then both $\left(c_{1} ; e_{1}\right) \in Z_{1}\left(E_{1}\right) \mid e_{1}=e_{\cap}+\varepsilon$ and $\left(c_{2} ; e_{2}\right) \in Z_{2}\left(E_{2}\right) \mid e_{2}=e_{\cap}-\varepsilon$ are included into $Z(E)$ by applying

Propositions 4 and 5. Let $\left(c_{3} ; e_{3}\right) \mid c_{3}=\frac{c_{1}+c_{2}}{2}, e_{3}=\frac{e_{1}+e_{2}}{2} .\left(c_{3} ; e_{3}\right) \in \operatorname{Conv}(Z(E))$, moreover, $\left(c_{3} ; e_{3}\right)$ dominates $\left\{c_{\cap} ; e_{\cap}\right\}$. This proves that $\operatorname{Eff}(\operatorname{Conv}(Z(E))) \neq Z(E)$ thus $Z(E)$ is non-convex. This conclude $\square$ the proof.

\section{Proof of Proposition 7:}

Assume that $\left(c_{k} ; e_{k}\right) \in Z_{k}\left(E_{k}\right)^{\cap}$ with $k \in[1 ; n]$. Then $\left(c_{k} ; e_{k}\right) \subset Z(E)$ by definition of an efficient solution thus $\bigcup_{k=1}^{n} Z_{k}\left(E_{k}\right)^{\cap} \subset Z(E)$. Let $(c ; e) \in Z(E)$. As $Z(E) \subset \bigcup_{k=1}^{n} Z_{k}\left(E_{k}\right)$, there exists $k \in[1 ; n]$ such that $(c ; e) \in Z_{k}\left(E_{k}\right)$. If $(c ; e) \notin Z_{k}\left(E_{k}\right)^{\cap}$, then it is a dominated element thus $(c ; e) \notin Z(E)$ which is a contradiction. Thus, $Z(E) \subset \bigcup_{k=1}^{n} Z_{k}\left(E_{k}\right)^{\cap}$. This proves that $Z(E)=\bigcup_{k=1}^{n} Z_{k}\left(E_{k}\right)^{\curvearrowleft}$. This concludes the proof. 


\section{Proof of Proposition 8:}

Assume that a price $\alpha$ is associated to the company's carbon emissions and assume that the company can decide between modes 1 and 2 with $Z_{C 1}^{*}<Z_{C 2}^{*}$ and $Z_{E 1}^{*}>Z_{E 2}^{*}$. For $\alpha=0$, we obtain that $Z_{C 1}^{*}<Z_{C 2}^{*}$. Moreover, there exists $\alpha_{2}$ such that $\min \left(Z_{1}(Q)+\alpha_{2} E_{1}(Q)\right)>\min \left(\left(Z_{2}(Q)+\alpha_{2} E_{2}(Q)\right)\right.$ as $Z_{E 1}^{*}>Z_{E 2}^{*}$ (when $\alpha$ tends to infinity, the influence of carbon emissions becomes dominant and $Z_{E 1}^{*}>Z_{E 2}^{*}$ ). By applying Lemma 2, we obtain that $\left|Z_{1}\left(E_{1}\right) \cap Z_{2}\left(E_{2}\right)\right| \leq 1$, thus, there is a unique common tangent between $Z_{1}\left(E_{1}\right)$ and $Z_{2}\left(E_{2}\right)$. Let $-\frac{1}{L_{C}}$ be the slope of this common tangent. We conclude that if $\alpha<L_{C}$, then $\min \left(Z_{1}(Q)+\alpha E_{1}(Q)\right)<\min \left(\left(Z_{2}(Q)+\alpha E_{2}(Q)\right)\right.$ If $\alpha>L_{C}$, then $\min \left(Z_{1}(Q)+\alpha E_{1}(Q)\right)>\min \left(\left(Z_{2}(Q)+\alpha E_{2}(Q)\right)\right.$ . This concludes the proof.

\section{References}

Absi, N., Dauzère-Pérès, S., Kedad-Sidhoum, S., Penz, B., Rapine, C., 2013. Lot sizing with carbon emission constraints. European Journal of Operational Research 227(1), 55-61.

Arslan, M.C., Turkay, M., 2013. EOQ Revisited with Sustainability Considerations. Foundations of Computing and Decision Science 38(4), 223-249.

Axsäter, S., 2006. Inventory control. Springer.

Battini, D., Persona, A., Sgarbossa, F., 2014. A sustainable EOQ model: Theoretical formulation and applications. International Journal of Production Economics, The Economics of Industrial Production 149, 145-153.

Bauer, J., Bektaş, T., Crainic, T.G., 2009. Minimizing greenhouse gas emissions in intermodal freight transport: an application to rail service design. Journal of the Operational Research Society 61(3), $530-542$.

Benjaafar, S., Li, Y., Daskin, M., 2013. Carbon Footprint and the Management of Supply Chains: Insights From Simple Models. IEEE Transactions on Automation Science and Engineering 10(1), 99 -116.

Bonney, M., Jaber, M.Y., 2011. Environmentally responsible inventory models: Non-classical models for a non-classical era. International Journal of Production Economics 133(1), 43-53.

Bouchery, Y., Ghaffari, A., Jemai, Z., Dallery, Y., 2012. Including sustainability criteria into inventory models. European Journal of Operational Research 222(2), 229-240.

Caro, F., Corbett, C.J., Tan, T., Zuidwijk, R., 2013. Double Counting in Supply Chain Carbon Footprinting. Manufacturing \& Service Operations Management 15(4), 545-558.

Chan, L.M.A., Muriel, A., Shen, Z.-J.M., Simchi-Levi, D., Teo, C.-P., 2002. Effective Zero-InventoryOrdering Policies for the Single-Warehouse Multiretailer Problem with Piecewise Linear Cost Structures. Management Science 48(11)446-1460. 
Chen, X., Benjaafar, S., Elomri, A., 2013. The carbon-constrained EOQ. Operations Research Letters 41(2), 172-179.

Cholette, S., Venkat, K., 2009. The energy and carbon intensity of wine distribution: A study of logistical options for delivering wine to consumers. Journal of Cleaner Production 17(16), 1401-1413.

Corbett, J.J., Wang, H., Winebrake, J.J., 2009. The effectiveness and costs of speed reductions on emissions from international shipping. Transportation Research Part D: Transport and Environment 14(8), 593-598.

Croxton, K.L., Gendron, B., Magnanti, T.L., 2003. Models and Methods for Merge-in-Transit Operations. Transportation Science 37(1), 1-22.

Dekker, R., Bloemhof, J., Mallidis, I., 2012. Operations Research for green logistics - An overview of aspects, issues, contributions and challenges. European Journal of Operational Research 219(3), 671-679.

Demir, E., Bektaş, T., Laporte, G., 2014. A review of recent research on green road freight transportation. European Journal of Operational Research 237(3), 775-793.

DHL, 2010. Delivering Tomorrow: Towards Sustainable Logistics. Deutsch Post DHL Report.

Ehrgott, M., 2005. Multicriteria Optimization. Birkhäuser.

Fransoo, J. C., Günther, H. O., Jammernegg, W., 2014. Environmental sustainability in supply chains. Flexible Services and Manufacturing Journal, 26(1-2), 1-4.

Fransoo, J.C., Lee, C.-Y., 2013. The Critical Role of Ocean Container Transport in Global Supply Chain Performance. Production and Operations Management 22(2), 253-268.

Geoffrion, A.M., 1968. Proper efficiency and the theory of vector maximization. Journal of Mathematical Analysis and Applications 22(3), 618-630.

Govindan, K., Sarkis, J., Jabbour, C.J.C., Zhu, Q., Geng, Y., 2014. Eco-efficiency based green supply chain management: Current status and opportunities. European Journal of Operational Research 233(2), 293-298.

Hickman, J., Hassel, D., Joumard, R., Samaras, Z., Sorenson, S., 1999. Methodology for calculating transport emissions and energy consumption. Transport Research Laboratory, Crowthorne, UK.

Hoen, K.M.R., Tan, T., Fransoo, J.C., Houtum, G.J. van, 2014. Effect of carbon emission regulations on transport mode selection under stochastic demand. Flexible Services and Manufacturing Journal 26(1), 170-195.

Hoen, K.M.R., Tan, T., Fransoo, J.C., van Houtum, G.-J., 2013. Switching Transport Modes to Meet Voluntary Carbon Emission Targets. Transportation Science 48(4), 592-608.

Hua, G., Cheng, T.C.E., Wang, S., 2011. Managing carbon footprints in inventory management. International Journal of Production Economics 132(2), 178-185.

Jaber, M.Y., Glock, C.H., El Saadany, A.M.A., 2013. Supply chain coordination with emissions reduction incentives. International Journal of Production Research 51(1), 69-82.

Kleindorfer, P.R., Singhal, K., Wassenhove, L.N., 2009. Sustainable Operations Management. Production and Operations Management 14(4), 482-492.

Konur, D., 2014. Carbon constrained integrated inventory control and truckload transportation with heterogeneous freight trucks. International Journal of Production Economics 153, 268-279. 
Konur, D., Schaefer, B., 2014. Integrated inventory control and transportation decisions under carbon emissions regulations: LTL vs. TL carriers. Transportation Research Part E: Logistics and Transportation Review 68, 14-38.

Konur, D., Schaefer, B. (2015). Economic and environmental comparison of grouping strategies in coordinated multi-item inventory systems. Journal of the Operational Research Society, in press.

Kopfer, H. W., Schönberger, J., Kopfer, H., 2014. Reducing greenhouse gas emissions of a heterogeneous vehicle fleet. Flexible Services and Manufacturing Journal, 26(1-2), 221-248.

Leal, I.C., D’Agosto, M. de A., 2011. Modal choice evaluation of transport alternatives for exporting bioethanol from Brazil. Transportation Research Part D: Transport and Environment 16(3), 201-207.

Linton, J.D., Klassen, R., Jayaraman, V., 2007. Sustainable supply chains: An introduction. Journal of Operations Management 25(6), 1075-1082.

NTM, 2008. Environmental data for international cargo transport. Technical report.

Pan, S., Ballot, E., Fontane, F., 2013. The reduction of greenhouse gas emissions from freight transport by pooling supply chains. International Journal of Production Economics 143(1), 86-94.

Quariguasi Frota Neto, J., Walther, G., Bloemhof, J., van Nunen, J.A.E.E., Spengler, T., 2009. A methodology for assessing eco-efficiency in logistics networks. European Journal of Operational Research 193(3), 670-682.

Retel Helmrich, M., Jans, R.F., van den Heuvel, W., Wagelmans, A.P.M., 2015. The Economic Lot-Sizing Problem with an Emission Capacity Constraint. European Journal of Operational Research 241(1), $50-62$.

Rieksts, B.Q., Ventura, J.A., 2008. Optimal inventory policies with two modes of freight transportation. European Journal of Operational Research 186(2), 576-585.

Rosič, H., Jammernegg, W., 2013. The economic and environmental performance of dual sourcing: A newsvendor approach. International Journal of Production Economics 143(1), 109-119.

Sarkis, J., Zhu, Q., Lai, K., 2011. An organizational theoretic review of green supply chain management literature. International Journal of Production Economics 130(1), 1-15.

Schaefer, B., Konur, D., 2015. Economic and environmental considerations in a continuous review inventory control system with integrated transportation decisions. Transportation Research Part E: Logistics and Transportation Review, 80, 142-165.

Scipioni, A., Manzardo, A., Mazzi, A., Mastrobuono, M., 2012. Monitoring the carbon footprint of products: a methodological proposal. Journal of Cleaner Production 36, 94-101.

Seuring, S., Müller, M., 2008. From a literature review to a conceptual framework for sustainable supply chain management. Journal of Cleaner Production 16(15), 1699-1710.

Srivastava, S.K., 2007. Green supply-chain management: A state-of-the-art literature review. International Journal of Management Reviews 9(1), 53-80.

Sundarakani, B., de Souza, R., Goh, M., Wagner, S.M., Manikandan, S., 2010. Modeling carbon footprints across the supply chain. International Journal of Production Economics 128(1), 43-50.

Tang, C.S., Zhou, S., 2012. Research advances in environmentally and socially sustainable operations. European Journal of Operational Research 223(3), 585-594. 
Velázquez-Martínez, J.C., Fransoo, J.C., Blanco, E.E., Mora-Vargas, J., 2014. The impact of carbon footprinting aggregation on realizing emission reduction targets. Flexible Services and Manufacturing Journal 26(1), 196-220.

Winebrake, J.J., Corbett, J.J., Falzarano, A., Hawker, J.S., Korfmacher, K., Ketha, S., Zilora, S., 2008. Assessing Energy, Environmental, and Economic Tradeoffs in Intermodal Freight Transportation. Journal of the Air \& Waste Management Association 58(8), 1004-1013.

World Commission on Environment and Development, 1987. Our Common Future. Oxford University Press. 